\title{
Geologia estrutural aplicada à mineração subterrânea de carvão em Araranguá (SC, Brasil)
}

\author{
Thales Sebben PETRY' ${ }^{1}$ Ruy Paulo PHILIPP² \& Clóvis GONZATTI ${ }^{2}$
}

\author{
${ }^{1}$ Programa de Pós-graduação em Geociências, Universidade Federal do Rio Grande do Sul. Av. Bento Gonçalves, 9.500, CEP \\ 91.540-000, Porto Alegre, RS, Brasil (thalesspetry@gmail.com). \\ ${ }^{2}$ Centro de Estudos em Petrologia e Geoquímica, Universidade Federal do Rio Grande do Sul. Av. Bento Gonçalves, 9.500, CEP \\ 91.540-000, Porto Alegre, RS, Brasil (ruy.philipp@ufrgs.br, gonzatti@ufrgs.br).
}

Petry, T.S., Philipp, R.P. \& Gonzatti, C. 2018. Geologia estrutural aplicada à mineração subterrânea de carvão em Araranguá (SC, Brasil). Pesquisas em Geociências, 45: e0656.

DOI: https://doi.org/10.22456/1807-9806.85644

Resumo. A mineração subterrânea na região carbonífera de Santa Catarina possui forte controle estrutural. A área de pesquisa da Mina D situa-se na porção NE do município de Araranguá. Este trabalho apresenta uma estimativa do arcabouço estrutural das rochas sedimentares e da camada de carvão Barro Branco na área de pesquisa através da avaliação integrada de imagens de satélite e dados de 100 furos de sondagem. As principais direções dos lineamentos identificadas nas imagens de satélite são $\mathrm{N} 30^{\circ}-60^{\circ} \mathrm{W}, \mathrm{N} 60^{\circ}-80^{\circ} \mathrm{E}$ e $\mathrm{N} 30^{\circ}-60^{\circ} \mathrm{E}$. 0 mapa de contorno estrutural da camada de carvão e as seções geológicas mostram que a área é afetada por falhas de direção $\mathrm{N} 30^{\circ}-60^{\circ} \mathrm{W}$, $\mathrm{N} 50^{\circ}-70^{\circ} \mathrm{E}, \mathrm{N} 10^{\circ}-20^{\circ} \mathrm{W}$ e E-W. As falhas de direção $\mathrm{NE}$ apresentam extensão regional e exercem significativa influência no arranjo estrutural da área. Nesses casos os rejeitos são expressivos $(>100$ m) e inviabilizam a recuperação econômica do carvão em algumas porções da área. A orientação das galerias deve ser de modo paralelo a estas falhas nas suas proximidades. As falhas de direção NW são as mais frequentes e possuem extensão e rejeitos menores $(<30 \mathrm{~m})$. 0 planejamento da lavra deve considerar esse sistema de falhas, evitando o cruzamento das mesmas. Falhas de direção N-S foram identificadas na área e apresentam rejeitos expressivos ( $>70 \mathrm{~m}$ ). Ocorrem ainda falhas inversas associadas ao soerguimento ocasionado por intrusões de diabásio. Próximo a estas áreas podem ocorrer zonas de acúmulo de tensões, geralmente associadas a problemas de instabilidade de teto e levantamento de piso. A metodologia aplicada demonstrou ser eficiente na estimativa das estruturas tectônicas e na avaliação preliminar da sua influência na mineração subterrânea de carvão.

Palavras-chave. Bacia do Paraná, Formação Rio Bonito, Geologia Estrutural, Lavra, Deformação rúptil.

Abstract. Structural geology aPPlied to the underground coAl mining in ARARANGUÁ (SC, BRAZIL). The underground coal mining in the carboniferous region of Santa Catarina state has a great structural control. The studied area is located in the NE portion of the Araranguá city. This research presents the structural data of the sedimentary rocks and the Barro Branco coal seam in the Mina $D$ area through the integrated evaluation of satellite images and 100 boreholes data. The major lineaments identified in the satellite images have $\mathrm{N} 30^{\circ}-60^{\circ} \mathrm{W}, \mathrm{N} 60^{\circ}-80^{\circ} \mathrm{E}$ and $\mathrm{N} 30^{\circ}-60^{\circ} \mathrm{E}$ directions. The coal seam structural contour map and the geological sections highlights the occurrence of faults which have $\mathrm{N} 30^{\circ}-60^{\circ} \mathrm{W}, \mathrm{N} 50^{\circ}-70^{\circ} \mathrm{E}, \mathrm{N} 10^{\circ}-20^{\circ} \mathrm{W}$ and $\mathrm{E}-\mathrm{W}$ directions. The $\mathrm{NE}$ direction faults have regional extension and are the most influent in the structural arrangement of the area. This faults have expressive tailings ( $>100 \mathrm{~m}$ ) and prevent the economic recovery of the coal in some portions of the area. The future mine galleries should be oriented parallel the main faults. The faults with NW direction is the most frequent and have minor extension and tailings $(<30 \mathrm{~m})$.The mining plan should consider it in order to avoid have to cross this faults. The N-S direction faults were identified in the area and presents expressive tailings ( $>70 \mathrm{~m}$ ). The occurrence of inverse faults is associated with the uplift related to the intrusion of diabase sills. Stress accumulation zones can occur close to this areas and are usually related to roof instability and floor heaving. The applied methods proved to be efficient in the estimation of tectonic structures and in the preliminary evaluation of their influence on underground coal mining.

Keywords. Paraná Basin, Rio Bonito Formation, Structural Geology, Mining, Brittle Deformation. 


\section{Introdução}

Mapas estruturais em escala regional e de detalhe são pré-requisito para qualquer atividade de mineração. A região carbonífera de Santa Catarina é, atualmente, a maior produtora de carvão mineral do Brasil e possui o carvão de melhor qualidade, classificado regionalmente como carvão betuminoso com alto teor de voláteis e alto teor de cinzas (Kalkreuth et al., 2010). 0 esgotamento das jazidas explotadas a céu aberto e das minas subterrâneas rasas levou à mineração do carvão a maiores profundidades, o que exige um maior conhecimento da geologia estrutural da área a ser minerada. A mineração subterrânea na região é desenvolvida pelo método de câmeras e pilares e, por isso, o conhecimento da geologia regional e local é fundamental para a segurança e economicidade da atividade.

A identificação e a caracterização das zonas de falhas e de áreas de intenso fraturamento são indispensáveis na execução de projetos de exploração de minas de carvão subterrâneas, sendo vital para o planejamento e operação da lavra (Nelson, 1991; Bailey et al., 2005; Phillipson, 2005a, 2005b). Além de afetar a estabilidade da escavação, as falhas deslocam as camadas de carvão. Antes de iniciar a atividade de mineração, bem como qualquer outro tipo de escavação em rocha, é necessário determinar as zonas de falhas, sua orientação, extensão, rejeito e características geotécnicas da maneira mais detalhada possível. A estabilidade de escavações subterrâneas em rochas sedimentares é influenciada, principalmente, pelo tipo de litologia, estruturas sedimentares, coesão da rocha, grau de faturamento e perfil do manto de alteração. Outro aspecto importante para o planejamento de lavra que é relacionado às zonas de falha é a estimativa local da magnitude e direção das tensões atuantes no maciço rochoso (Peng, 1986; Brady \& Brown, 2005). Determinados tipos de falha, principalmente as geradas sob regimes tectônicos compressivos como as falhas inversas, acumulam tensões horizontais que, somadas às tensões induzidas pela escavação, podem gerar zonas de instabilidade na mina (Krebs, 2004; Brady \& Brown, 2005). A análise estrutural da região através de imagens de satélite e a interpretação do arcabouço estrutural da camada de carvão através de dados de furos de sondagem proporcionam uma estimativa da disposição espacial e do rejeito das zonas de falha e a confecção de um mapa estrutural que permite avaliar os riscos associados às zonas de falhas.

A região carbonífera de Santa Catarina compreende as rochas sedimentares e vulcânicas situadas na porção sudeste da Bacia do Paraná. A origem e evolução da bacia são relacionadas à reativação tectônica de estruturas do embasamento Pré-cambriano (Almeida, 1967, 1969, 1980; Zalán et al., 1987; Holz et al., 2006). Estes eventos exerceram forte influência no arcabouço estrutural da bacia desde a sua origem no Neo-Ordoviciano, marcando períodos de atividade tectônica rúptil extensional e transcorrente, com geração de espaço de acomodação e sedimentação (Rostirolla et al., 2000; Holz et al., 2006). Estruturas de escalas e características variadas foram geradas, desde estruturas regionais, como o Arco de Ponta Grossa (Almeida, 1983; Strugale et al., 2007), até falhas que condicionaram localmente a sedimentação (Zalán et al., 1987; Soares, 1991; Krebs, 2004). Os estágios de formação do magmatismo Serra Geral e ruptura do supercontinente Gondwana, entre o Neo-Jurássico e o Eocretáceo, tiveram uma importante influência no arcabouço estrutural da área de pesquisa da Mina D, que se situa próximo ao domínio da Bacia de Pelotas (Gonçalves et al., 1979; Krebs, 2004).

O objetivo deste trabalho é avaliar a geologia estrutural da região de Araranguá para estimar o arcabouço estrutural das rochas sedimentares e da camada de carvão Barro Branco na área da futura Mina D. Esta análise tem como base a avaliação dos lineamentos por imagens de satélite, associada com as informações obtidas nos furos de sondagem disponibilizados pela empresa Maracajá Mineração S.A.

\section{2 Área, materiais e métodos}

A região carbonífera de Santa Catarina está localizada na região sudeste da Bacia do Paraná em uma área composta por rochas sedimentares e vulcânicas (Fig. 1). Esta bacia é composta por um pacote de rochas sedimentares e vulcânicas 
subdivididas em seis supersequências de segunda ordem, com intervalo deposicional entre o Neo -Ordoviciano e o Neocretáceo; apresenta cerca de $7.000 \mathrm{~m}$ de espessura e define um registro estratigráfico de quase 400 Ma (Milani et al., 2007).

A região carbonífera catarinense se situa na porção sul do estado de Santa Catarina e compreende vários municípios que possuem a minera- ção de carvão como uma das principais atividades econômicas e fonte de empregos formais. A área de pesquisa de carvão mineral da Mina $\mathrm{D}$, concedida à empresa Maracajá Mineração S.A., se localiza na parte sudeste da região carbonífera, entre a BR101 e o litoral, e abrange os municípios de Araranguá, Içara e Balneário Rincão (Fig. 2).

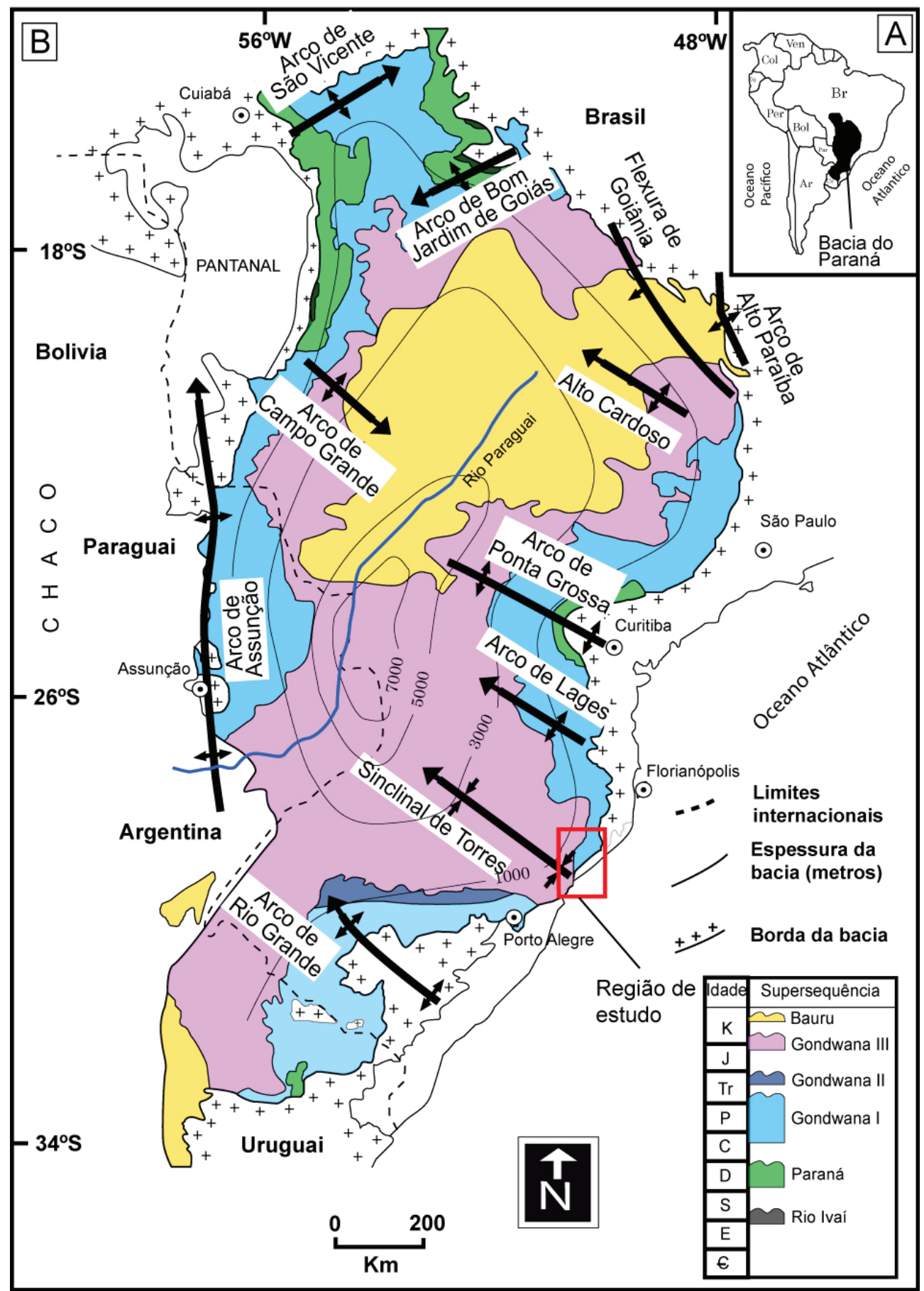

Figura 1. Mapas da Bacia do Paraná. A) Localização da Bacia do Paraná na América do Sul; B) Mapa geológico simplificado da Bacia do Paraná mostrando o contato das rochas sedimentares com o embasamento, a distribuição das supersequências deposicionais e as estruturas de grande escala (modificado de Milani, 2004). 0 retângulo vermelho destaca a localização da região carbonífera de Santa Catarina.

Figure 1. Paraná Basin maps. A) Location of the Paraná Basin in the South America; B) Simplified geological map of the Paraná Basin showing the basement contacts, the distribution of the deposicional supersequences and the large-scale structures (modified from Milani, 2004). The red rectangle highlights the location of the carboniferous region of Santa Catarina state. 


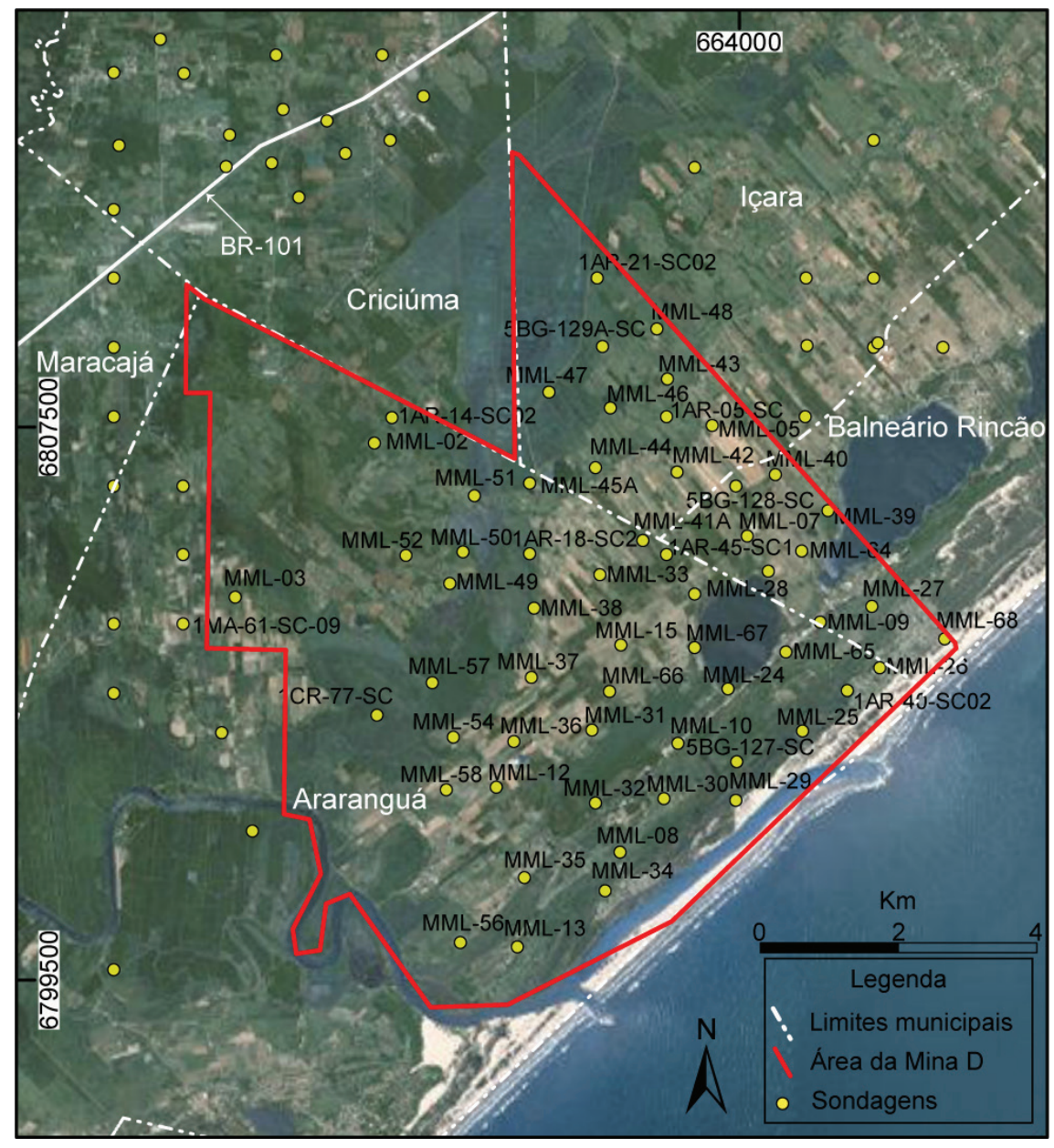

Figura 2. Imagem de satélite mostrando a localização e os limites da área de pesquisa da Mina D, os limites municipais e a localização dos furos de sondagem.

Figure 2. Satellite image showing the localization and the limits of the research area of Mina D, the cities limits and the location of the boreholes.

\subsection{Geologia da área}

A Bacia do Paraná é uma bacia intracratônica e sua origem e evolução são atribuídas à geração de espaço de acomodação pela reativação tectônica rúptil extensional e transcorrente das zonas de cisalhamento dúcteis NE-SW e NW-SE do embasamento pré-cambriano em resposta as orogêneses andinas da borda oeste do Gondwana (Almeida, 1980, 1981; Zalán et al., 1987; Soares, 1991; Milani \& Ramos, 1998; Rostirolla et al., 2000; Holz et al., 2006). A deposição dos sedimentos do Grupo Itararé e da Formação Rio Bonito, que constituem a porção basal da Supersequência Gondwana I (Milani et al., 2007), ocorreu em um período tectonicamente ativo na bacia com forte controle estrutural por falhas de direção NE (Northfleet et al., 1969; Zalán et al., 1987; Soares, 1991). A movimentação das falhas foi responsável pelo soerguimento das áreas fonte a leste gerando um grande aporte de sedimentos (Zalán et al., 1987) e tam- bém pela formação de baixos estruturais onde se observa o espessamento da sequência sedimentar destas formações (Zalán et al., 1987; Soares, 1991; Krebs, 2004). Muitos trabalhos com foco na geologia estrutural foram realizados em diferentes regiões da bacia. As deformações associadas à reativação das estruturas herdadas do embasamento geraram estruturas em flor (Rostirolla et al., 2000; Krebs, 2004), sinformes e antiformes (Fabrício et al., 1972b; Krebs et al., 1982, 1983), dobras e falhas inversas escalonadas (Soares, 1991), falhas normais e falhas transcorrentes (Zalán et al., 1987; Ferreira \& Almeida, 1989; Soares, 1991; Strugale et al., 2007). Ocorrem também deformações associadas às intrusões das rochas ígneas que geraram falhas inversas pelo soerguimento de blocos (Zalán et al., 1987; Krebs, 2004).

Na região carbonífera de Santa Catarina ocorrem rochas sedimentares e vulcânicas da Bacia do Paraná e rochas do embasamento Pré-cambriano (Fig. 3). Os trabalhos de pesquisa para car- 
vão realizados pelo convênio DNPM/CPRM entre 1971 e 1986 apresentam, entre outros aspectos, as feições estruturais de diferentes áreas da região carbonífera de Santa Catarina, identificadas através da interpretação de fotografias aéreas, trabalhos de campo, construção de seções geológicas e de mapas de contorno estrutural das camadas de carvão (Fabrício et al., 1972a, 1972b, 1973; Krebs et al., 1982, 1983; Aboarrage \& Lopes, 1986). Nestes trabalhos são reportadas falhas de direção NE-SW, NW-SE, N-S e E-W descritas como falhas normais. As camadas sedimentares na região carbonífera de Santa Catarina apresentam um suave mergulho regional de aproximadamente 2 a $3^{\text {o }}$ para SW (Fig. 4A) (Fabrício et al., 1972a, 1979; Krebs et al., 1982). Este comportamento estrutural está relacionado ao aprofundamento das camadas em sentido a Sinclinal de Torres (Fig. 4A), situada a SW da região carbonífera, onde o mergulho das camadas é suavizado (Süffert, 1976; Fabrício et al., 1979).

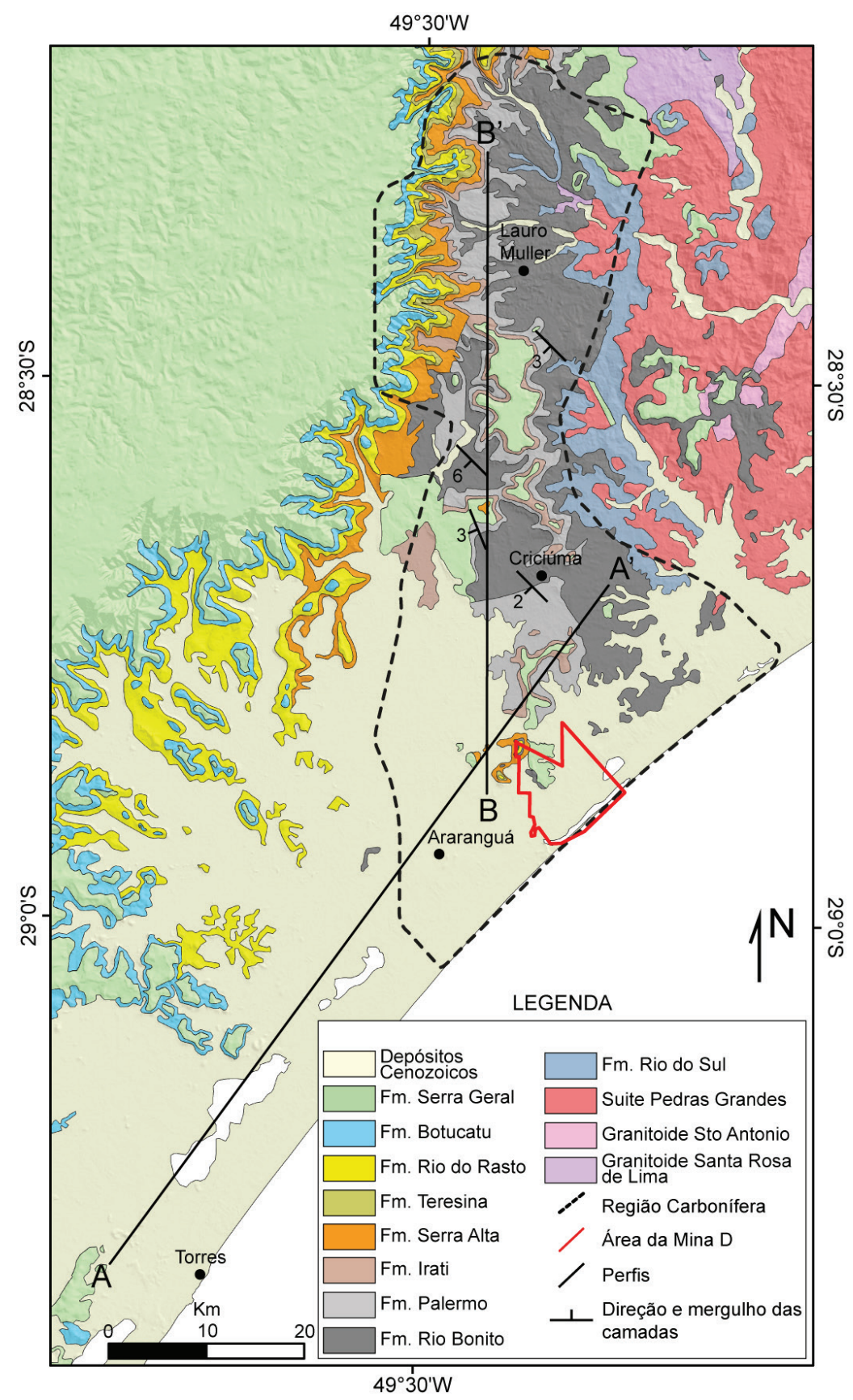

Figura 3. Mapa geológico da região carbonífera de Santa Catarina e áreas adjacentes com valores médios de mergulho e atitudes das camadas (extraído e modificado de Wildner et al., 2014). 0 polígono vermelho destaca a localização da área da Mina D. Figure 3. Geological map of the carboniferous region of the Santa Catarina state, with dip and direction of the strata (extracted and modified from Wildner et al., 2014).The red poligon highlights the location of the Mina D area. 
Em estudo hidrogeológico na bacia hidrográfica do Rio Araranguá com abrangência na área de pesquisa deste trabalho, Krebs (2004) aborda os aspectos estruturais da região através da interpretação de fotos aéreas, seções geológicas e de observações em minas de carvão subterrâneas. Neste trabalho foram identificados falhamentos de direção $\mathrm{N} 05^{\circ}-30^{\circ} \mathrm{W}$ e $\mathrm{N} 45^{\circ}-75^{\circ} \mathrm{E}$ e, subordinadamente, $\mathrm{N}-\mathrm{S}, \mathrm{N} 30^{\circ}-45^{\circ} \mathrm{E}, \mathrm{N} 30^{\circ}-45^{\circ} \mathrm{W}$ e E-W. As falhas de direção $\mathrm{N} 05^{\circ}-30^{\circ} \mathrm{W}$ podem apresentar rejeitos verticais expressivos, superiores a $30 \mathrm{~m}$, e controlam calhas estruturais e altos do embasamento, o que sugere se tratar de falhas sin-sedimentares (Krebs, 2004). Diques de diabásio ocorrem encaixados nas falhas deste sistema indicando se tratar de um sistema de falhas extensional (Krebs, 2004), interpretado como sendo um dos principais alimentadores do vulcanismo Serra Geral (Strugale et al., 2007). 0 sistema de falhas de direção $\mathrm{N} 45^{\circ}$ $-75^{\circ} \mathrm{E}$ apresenta os maiores rejeitos, por vezes superiores a $40 \mathrm{~m}$, e intersecta e desloca as falhas do

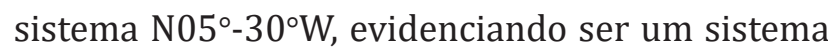
de falhas mais jovem. 0 sistema de falhas de direção N-S possui falhas extensas e que geralmente encaixam diques de diabásio, indicando um caráter extensional. As falhas de direção $\mathrm{N} 30^{\circ}-45^{\circ} \mathrm{E}$ e $\mathrm{N} 30^{\circ}-45^{\circ} \mathrm{W}$ ocorrem associadas às falhas de outro sistema, o que sugere se tratar de falhas sintéticas e antitéticas (Krebs, 2004). As falhas de direção E-W têm origem relacionada aos eventos de ruptura do Gondwana (Zalán et al., 1987; Strugale et al., 2007). A região correspondente à bacia hidrográfica do Rio Araranguá apresenta um comportamento estrutural homogêneo disposto em uma grande homoclinal com mergulho suave para S-SW (inferior a $3^{\circ}$ ) (Krebs, 2004). Além do suave mergulho regional dos estratos em sentido a Sinclinal de Torres (Fig. 4A), a região carbonífera apresenta um aprofundamento das camadas sedimentares em sentido SE (Fig. 4B). Na área próxima ao litoral, a leste da BR-101, é observado um rápido afundamento das rochas sedimentares devido à presença de extensas falhas de direção NE-SW que apresentam rejeitos expressivos, por vezes superiores a $100 \mathrm{~m}$, e ocasionam o rebaixamento e um suave basculamento das camadas para SW (Gonçalves et al., 1979; Krebs, 2004). Os primeiros estágios da ruptura do Gondwana, atribuídos ao Eocretáceo, geraram faixas falhadas subparalelas à costa com a formação de extensos grabens assimétricos (Gonçalves et al., 1979; Krebs, 2004).

0 embasamento cristalino na região é constituído pelas rochas graníticas da Suíte Pedras Grandes e por complexos granito-gnáissicos e compreende a porção sul do Batólito Florianópolis (Fig. 3) (Silva et al., 2000; Bitencourt et al., 2008). 0 complexo granito-gnáissico é composto pelos granitoides Santa Rosa de Lima, Santo Antônio e Paulo Lopes, que apresentam composições sieno e monzograníticas, subordinadamente granodioríticas, com texturas porfiríticas e foliação de fluxo ígneo, localmente desenvolvendo foliação milonítica. Estes granitoides ocorrem como corpos alongados com orientação $\mathrm{N} 20^{\circ}-30^{\circ} \mathrm{E}$ e apresentam um posicionamento sin-transcorrente as zonas de cisalhamento dúcteis da orogênese brasiliana (Silva et al., 2000; Bitencourt et al., 2008). A Suíte Pedras Grandes compreende, predominantemente, o Granito Imaruí-Capivari, com ocorrência de corpos graníticos menores. As principais litologias são biotita e hornblenda monzogranitos, que apresentam características geoquímicas de granitos póscolisionais (Jelinek et al., 2005). Os lineamentos estruturais possuem direções NW-SE, NNW, NNE e NE-SW.

A Bacia do Paraná na região carbonífera de Santa Catarina compreende as supersequências deposicionais Gondwana I e Gondwana III, depositadas entre o Neocarbonífero e o Eocretáceo (Milani et al., 2007). Na área de pesquisa foram identificadas, através de furos de sondagem, parte das formações que compõem a Supersequência Gondwana I, de idade Permiana. As rochas da Formação Rio do Sul, topo do Grupo Itararé, são encontradas na base de alguns furos de sondagem. As litologias da formação incluem arenitos com estratificação cruzada ou plano paralela, arenitos com estrutura de fluidização, siltitos e intercalações rítmicas de siltitos e arenitos, depositados em ambiente de leques submarinos com influência glacial (Schneider et al., 1974). Recobrindo concordantemente a Formação Rio do Sul ocorrem as formações Rio Bonito e Palermo, do Grupo Guatá. A Formação Rio Bonito é subdividida nos membros Triunfo, Paraguaçu e Siderópolis (Schneider et al., 1974). No membro basal da formação predo- 


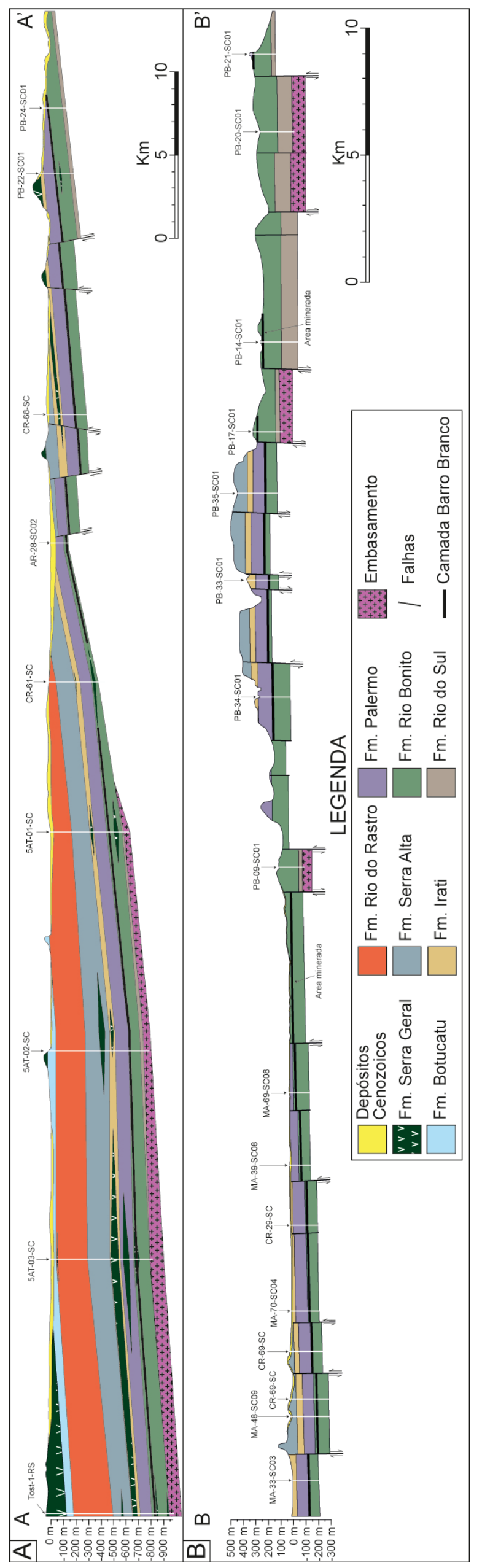

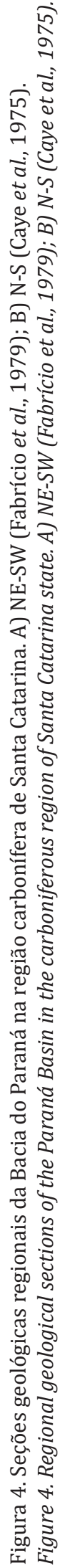


minam arenitos com estratificação plano-paralela e cruzada acanalada formados pela progradação de um sistema flúvio-deltaico sobre os leques submarinos da Formação Rio do Sul (Schneider et al., 1974; Holz, 1998). De modo subordinado ocorrem siltitos carbonosos laminados e camadas de carvão de importância econômica, principalmente a camada Bonito Inferior. O Membro Paraguaçu, depositado durante a transgressão marinha sobre o membro basal, é composto por arenitos finos com estratificação plano-paralela, siltitos laminados e intercalações entre as duas fácies. 0 Membro Siderópolis constitui a parte superior da formação e é composto por arenitos com estratificação plano-paralela, siltitos laminados e carbonosos e heterolitos com estruturas "flaser", "wavy" e "linsen", por vezes bioturbados. A deposição das rochas do Membro Siderópolis ocorreu em ambiente costeiro de laguna-barreira com influência fluvial (Holz, 1998). No membro superior ocorre a camada de carvão Barro Branco, que foi formada em ambiente pantanoso situado atrás da barreira litorânea (Holz, 1998). A porção superior do Grupo Guatá é composta pela Formação Palermo, que consiste principalmente em heterolitos "wavy" e "linsen", com a ocorrência de siltitos laminados e, subordinadamente, arenitos com estratificação cruzada acanalada, margas e calcários. A ocorrência de bioturbação é frequente e muito intensa em alguns intervalos da formação. A deposição das rochas da Formação Palermo é atribuída a um ambiente marinho transgressivo sob influência de ondas e marés (Lopes et al., 1986).

As formações Irati e Serra Alta, pertencentes ao Grupo Passa Dois, sucedem as do Grupo Guatá. A Formação Irati é dividida nos membros Taquaral e Assistência (Schneider et al., 1974) e foi formada em ambiente marinho de águas calmas, abaixo do nível das ondas, devido à restrição da circulação das correntes marinhas (Milani et al., 2007). Os depósitos são de folhelhos e folhelhos betuminosos, margas e calcários, com a ocorrência de siltitos e arenitos em menor volume (Schneider et al., 1974). A Formação Serra Alta recobre os folhelhos da Formação Irati e o contato entre as formações é transicional. A sua deposição é atribuída a um ambiente marinho de baixa energia (Milani $e t$ al., 2007). As rochas da formação são constituídas por siltitos laminados e folhelhos e intercalações entre os dois (Schneider et al., 1974).

As rochas vulcânicas Formação Serra Geral de idade Eocretácea recobrem as rochas sedimentares da Bacia do Paraná, com exceção da Supersequência Bauru. Este intenso vulcanismo de origem fissural formou uma espessa pilha de basaltos toleíticos e andesitos basálticos com estruturas tipo pahoehoe e a'a (Waichel et al., 2012). A porção superior é composta por lavas ácidas, de composição riolítica a riodacítica. Na região carbonífera ocorrem derrames de lava básica, além de diques e soleiras de diabásio (Krebs, 2004). Muitos morros são sustentados topograficamente por estes corpos intrusivos. A ascensão e o posicionamento das intrusões são controlados por jogos de falhas extensionais e sistemas de fraturas (Zalán et al., 1987; Strugale et al., 2007) que ainda ativam os planos de acamamento das rochas sedimentares formando extensas soleiras que, na região carbonífera, se posicionam principalmente no intervalo estratigráfico da Formação Irati (Krebs, 2004). 0 enxame de diques de Florianópolis, que se situa a norte da região carbonífera, é interpretado como sendo um alimentador do vulcanismo Serra Geral e possui orientação preferencial NNE (Florisbal et al., 2014). A área de pesquisa da Mina D é recoberta pelos depósitos cenozoicos da Planície Costeira de Santa Catarina. Os sedimentos são associados ao Sistema Laguna-Barreira e compreendem depósitos lagunares, deltaicos, paludiais, praiais marinhos e eólicos (Krebs, 2004). A presença desta cobertura sedimentar recente impede a observação dos lineamentos por imagens de satélite na área.

\subsection{Materiais e métodos}

O desenvolvimento desta pesquisa tem como base a revisão bibliográfica, a análise de imagens de satélite, descrição de furos de sondagem, integração espacial de banco de dados de sondagem e confecção de seções geológicas da área de carvão a ser minerada. A caracterização estrutural por meio da interpretação de imagens de satélite é uma ferramenta de fácil acesso e muito utilizada na avaliação da deformação rúptil em diversas áreas da Bacia do Paraná (Krebs, 2004; Strugale et al., 
2007; Roldan et al., 2010; Jacques et al., 2010). A análise dos lineamentos em imagens de satélite foi realizada em uma área de $20.000 \mathrm{~km}^{2}$, abrangendo toda a região carbonífera de Santa Catarina, parte do embasamento e do Planalto da Serra Geral. Foram utilizadas imagens Landsat 8, disponíveis no programa ArcGis, e imagens de relevo sombreado, disponíveis no Geobank da CPRM. Três escalas de trabalho foram utilizadas: 1:500.000, 1:250.000 e 1:20.000, de modo a permitir a observação de feições geológicas de diferentes escalas. A partir dos lineamentos traçados no programa ArcGis foi gerada uma tabela de dados azimutais dos lineamentos através da extensão Azimuth Finder (Queiroz et al., 2014). Com a tabela de dados azimutais foram gerados os diagramas de roseta de frequência e de comprimento acumulados, através do programa Stereonet 9.5 (Cardozo \& Allmendinger, 2013). Adicionalmente, foram gerados diagramas de frequência acumulada dos lineamentos nas diferentes unidades litológicas da região, a fim visualizar as direções predominantes em cada unidade.

Para a interpretação estrutural da área de pesquisa da Mina D foram utilizados os dados de 100 furos de sondagem, compreendendo cerca de $30.000 \mathrm{~m}$ totais de perfuração (Fig. 2). Os furos de sigla MML foram realizados pela empresa Maracajá Mineração S.A. e os furos com siglas AR, CR, BG, MA, foram realizados pelo convênio DNPM/CPRM. A camada de carvão Barro Branco é a mais superficial e economicamente importante na região. Por apresentar continuidade lateral e ampla ocorrência na região carbonífera de Santa Catarina, a camada foi utilizada como horizonte para os mapas de contorno estrutural na área da Mina D. A interpolação das cotas de lapa da camada foi realizada utilizando diferentes algoritmos de interpolação do programa ArcGis (Inverso da Distância Ponderada, Krigagens e Mínima Curvatura). Os modelos obtidos com os métodos testados apresentaram resultados semelhantes. 0 método Inverso da Distância Ponderada (IDW) apresentou os melhores resultados por criar o modelo mais fiel aos dados e destacar as anomalias locais, interpretadas como zonas de falha. Além de ter apresentado os melhores resultados para a interpretação estrutural da área, o método possibilitou inserir as falhas traçadas como barreiras na interpolação das cotas de lapa da camada de carvão. Cabe ressaltar que este tipo de modelagem contém certo grau de incerteza e o mapa estrutural gerado apresenta uma estimativa das zonas de falha na área de pesquisa. A partir das descrições dos testemunhos de sondagem foram confeccionadas nove seções geológicas utilizando o programa AutoCAD e o programa Adobe Illustrator. As falhas estimadas na área de pesquisa foram definidas através da leitura do mapa de contorno estrutural da lapa da camada de carvão Barro Branco e das seções geológicas. Após a interpretação do arcabouço estrutural da área estudada foi realizada uma nova interpolação IDW utilizando as falhas como barreiras, com a geração do mapa estrutural da área da Mina D e com a inserção das falhas nas seções geológicas. A estimativa do arcabouço estrutural e o mapa estrutural gerado possibilitam a adaptação do projeto de explotação da Mina D levando em consideração as condicionantes geológicas da área, neste caso as zonas de falha.

\section{Resultados}

\subsection{Análise dos lineamentos}

A interpretação das imagens de satélite e a confecção dos diagramas de roseta mostraram que as principais direções dos lineamentos na área são $\mathrm{N} 30^{\circ}-60^{\circ} \mathrm{W}, \mathrm{N} 60^{\circ}-80^{\circ} \mathrm{E}$ e $\mathrm{N} 30^{\circ}-60^{\circ} \mathrm{E}$ (Fig. 6). De modo subordinado ocorrem lineamentos de direção $\mathrm{N} 60^{\circ}-80^{\circ} \mathrm{W}, \mathrm{N} 10^{\circ}-30^{\circ} \mathrm{E}, \mathrm{N} 10^{\circ}-30^{\circ} \mathrm{W}$, $\mathrm{N}-\mathrm{S}$ e E-W. Os lineamentos observados compreendem majoritariamente feições negativas de relevo, principalmente vales e drenagens encaixadas, que são expostas em segmentos retilíneos. A imagem de satélite da figura 5B apresenta os lineamentos identificados na região carbonífera de Santa Catarina e adjacências. Os diagramas de roseta de frequência acumulada (Fig. 6A) e de comprimento acumulado (Fig. 6B) apresentam o resultado da análise estatística empregada. Além dos diagramas que consideram toda a área analisada foram confeccionados quatro diagramas que apresentam as direções dos lineamentos que ocorrem nas diferentes unidades litológicas da região (Fig. 6C, D, E e F).

Os lineamentos de maior frequência na 
área têm direção $\mathrm{N} 30^{\circ}-60^{\circ} \mathrm{W}(\mathrm{n}=750)$ e apresentam o comprimento dos traços uniforme, em geral entre 2 e $4 \mathrm{~km}$; estão distribuídos em toda a área analisada e ocorrem com menor espaçamento e maior persistência em um faixa de direção NW-SE com cerca de $80 \mathrm{~km}$ de extensão, entre as cidades de Torres e Criciúma, que se estende da Planície Costeira até o Planalto da Serra Geral. Esse é um dos principais sistemas de falhas que afeta todas as unidades litológicas da região e o que apresenta maior frequência na Formação Rio Bonito e nas demais rochas sedimentares da Bacia do Paraná (Fig. 6D e E). No planalto da Serra Geral o sistema é um condicionante do relevo, controlando a orientação das drenagens e dos vales da escarpa da serra. No embasamento cristalino estes lineamentos ocorrem de forma esparsa e na planície costeira, ao sul da região carbonífera, controlam o alonga- mento dos morros compostos por rochas da Bacia do Paraná.

Os lineamentos de direção $N 60^{\circ}-80^{\circ} \mathrm{E}$ $(n=599)$ apresentam os traços de maior comprimento, atingindo até $17 \mathrm{~km}$ de extensão. Estes lineamentos são identificados em todas as unidades litológicas da região e apresentam espaçamento constante, exceto na porção sul da região, próximo a Torres, onde ocorre o adensamento das falhas. É o sistema de falhas predominante nas rochas vulcânicas da Formação Serra Geral (Fig. 6F). No Planalto da Serra Geral estes lineamentos têm forte influência no relevo, encaixando drenagens e vales. Os lineamentos de direção N30 ${ }^{\circ}-60^{\circ} \mathrm{E}(\mathrm{n}=364)$, apesar de apresentarem frequência e comprimento consideráveis na região, ocorrem com expressividade apenas na Formação Serra Geral (Fig. 6F). Esse sistema de lineamentos possui ocorrência su-

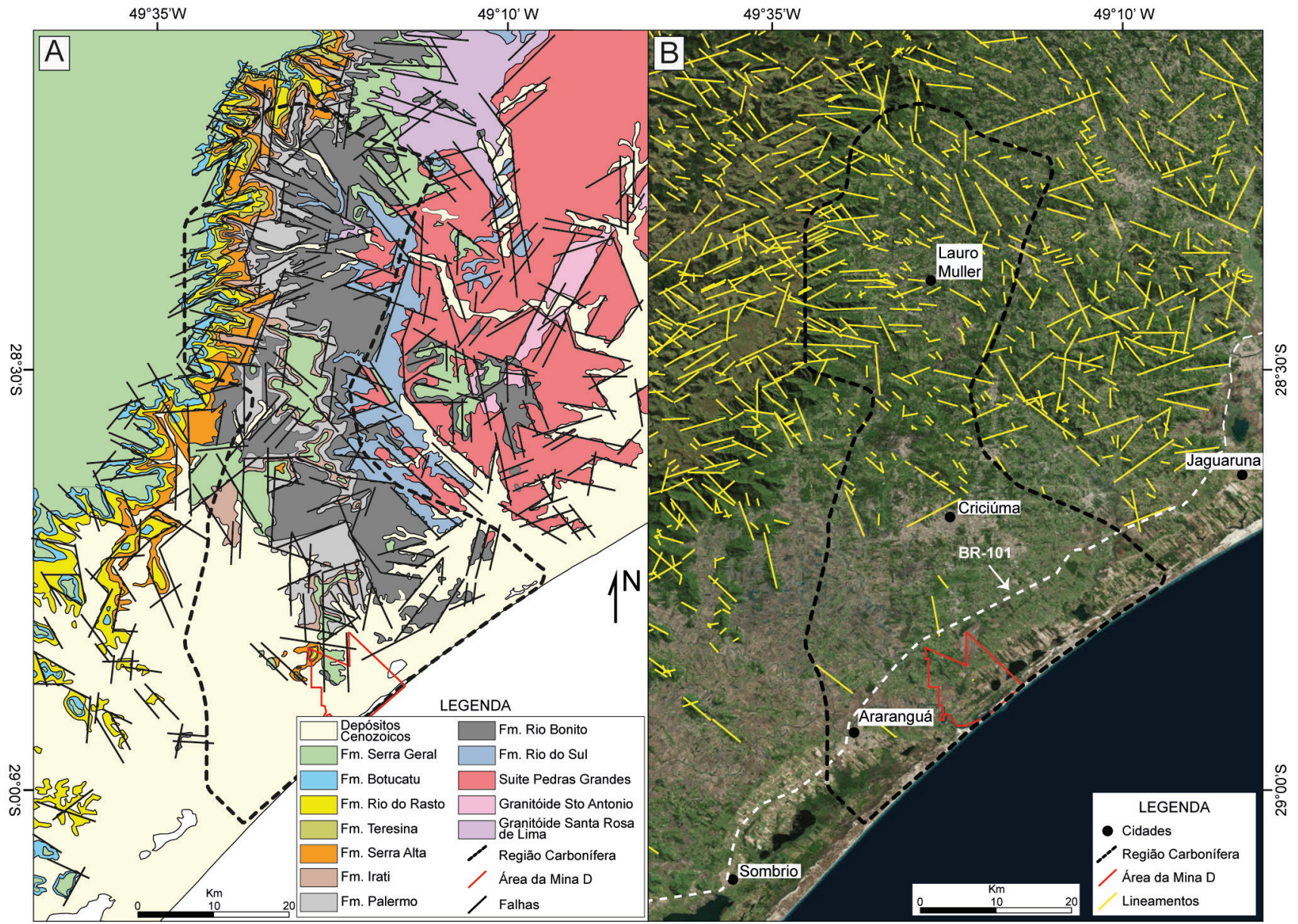

Figura 5. Mapas da região carbonífera de Santa Catarina. A) Mapa geológico da região carbonífera de Santa Catarina e adjacências (extraído e modificado de Wildner et al., 2014); B) Imagem de satélite com os lineamentos, as áreas correspondentes a região carbonífera de Santa Catarina e a Mina D delimitadas e as principais cidades da região.

Figure 5. Maps of the carboniferous region of Santa Catarina state. A) Geological map of the carboniferous region of the Santa Catarina state (extracted and modified from Wildner et al., 2014); B) Satellite image with lineaments, highlighting in the red line the corresponding area of Mina D and in black line, the limit of the carboniferous region of Santa Catarina state and the main cities. 


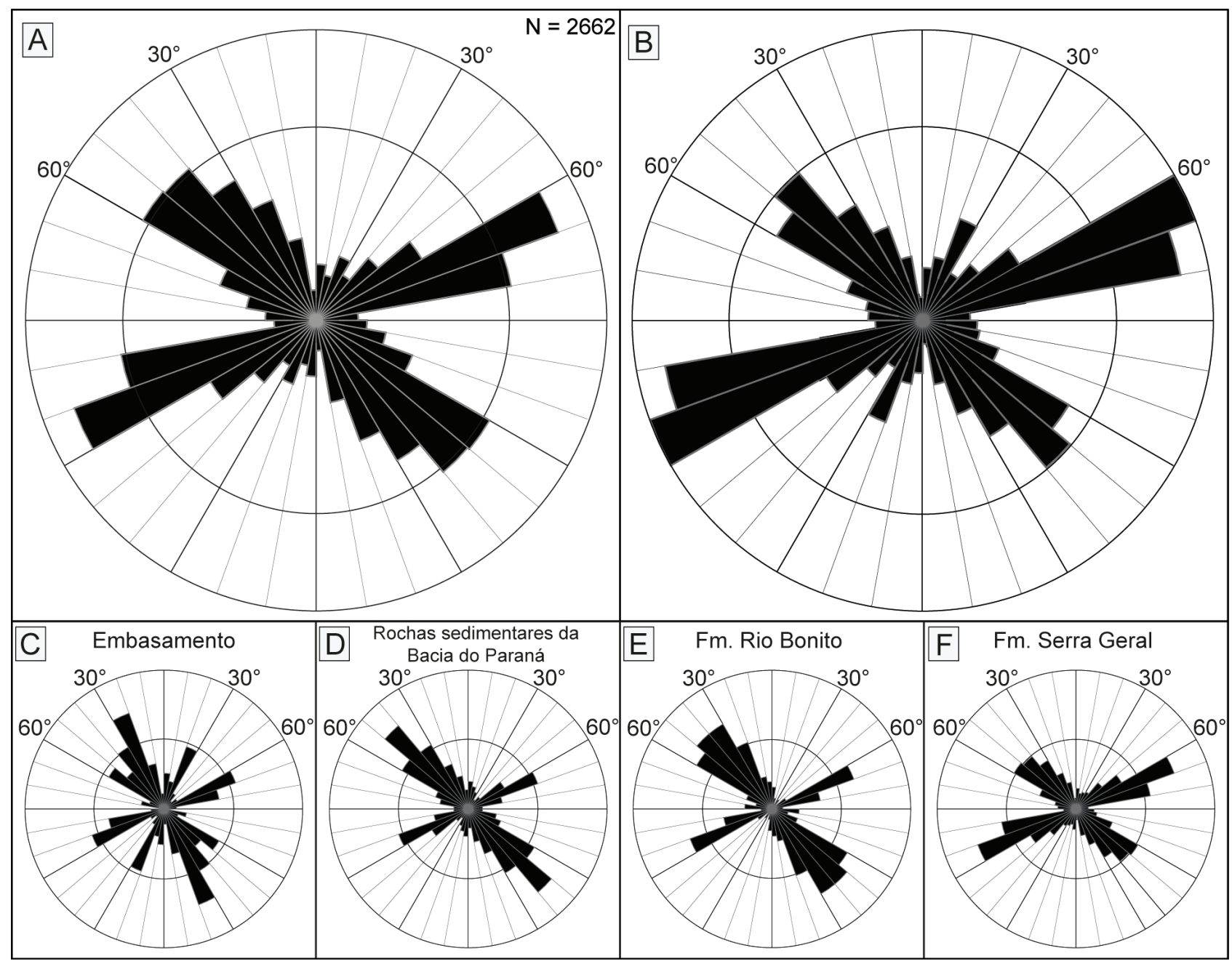

Figura 6. Diagramas de roseta dos lineamentos da área analisada. A) Frequência acumulada; B) Comprimento acumulado; C) Frequência acumulada nas rochas do embasamento; D) Frequência acumulada nas rochas sedimentares da Bacia do Paraná; E) Frequência acumulada na Formação Rio Bonito; F) Frequência acumulada na Formação Serra Geral.

Figure 6. Rose diagrams of the lineaments in the analyzed area. A) Accumulated frequency; B) Accumulated length; C) Accumulated frequency in the basement rocks; D) Accumulated frequency in the sedimentary rocks os Paraná Basin; E) Accumulated frequency in the Rio Bonito Formation; F) Accumulated frequency in the Serra Geral Formation.

bordinada nas demais unidades litológicas.

Os lineamentos de direção $\mathrm{N} 10^{\circ}-30^{\circ} \mathrm{W}$ $(\mathrm{n}=272)$ e $\mathrm{N} 10^{\circ}-30^{\circ} \mathrm{E}(\mathrm{n}=161)$ se distribuem de maneira esparsa na região e apresentam comprimentos variáveis, variando de poucas centenas de metros a mais de $10 \mathrm{~km}$. Os dois sistemas apresentam maior frequência nas rochas do embasamento (Fig. 6C), destacando os lineamentos de direção NW.

\subsection{Mapa de Contorno Estrutural}

A partir do arranjo estrutural observado com a interpretação estrutural dos lineamentos e das principais direções de lineamento identificadas na região carbonífera, foi possível estimar o arcabouço estrutural da área da Mina D. A interpretação estrutural da área da Mina D foi realizada através da análise do mapa de contorno estrutural da lapa da camada de carvão Barro Branco (Fig. 7A) e da interpretação das seções geológicas confeccionadas (Figs. 8 e 9). A interpretação visa estimar o arranjo estrutural da área, as direções das falhas e seus rejeitos, além de verificar se há relação temporal entre as estruturas identificadas e as variações na espessura da Formação Rio Bonito e da camada de carvão. A camada de carvão Barro Branco é identificada em quase todos os furos de sondagem na área da mina e nos furos adjacentes, exceto naqueles em que foi cortada por soleiras de diabásio. A espessura da camada de carvão varia entre 0,44 e 2,46 m e a espessura de carvão na camada varia entre 0,20 e 1,39 m. A cota de lapa da camada Barro Branco varia entre -76 e -378 m. A presença de soleiras de diabásio pode induzir ao erro na interpretação do mapa de contorno 
estrutural, visto que estes corpos ígneos podem deslocar as camadas. Nas seções geológicas são identificados corpos ígneos intrusivos de espessura e extensão lateral variáveis, desde corpos com $2 \mathrm{~m}$ de espessura e sem continuidade lateral, até corpos com mais de $100 \mathrm{~m}$ de espessura e extensão lateral de mais de $6 \mathrm{~km}$ (Fig. 8B). As intrusões pouco espessas e sem continuidade lateral são interpretadas como diques de diabásio, enquanto as intrusões espessas e que apresentam continuidade entre os furos de sondagem são interpretadas como soleiras de diabásio. Uma soleira de diabásio é identificada no intervalo estratigráfico da Forma- ção Irati em todas as seções geológicas realizadas e possui uma área de aproximadamente $22 \mathrm{~km}^{2}$, que abrange a porção central e parte da porção leste da área de pesquisa, e espessura variando entre 43 e $135 \mathrm{~m}$.

O mapa de contorno estrutural da lapa da camada de carvão integrado com as falhas foi realizado para a área de pesquisa, onde a malha de furos de sondagem é mais densa, o que permitiu uma interpretação mais precisa (Fig. 7A). As nove seções geológicas confeccionadas têm direções NW-SE e NE-SW e cortam perpendicularmente as principais estruturas na área. As quatro seções

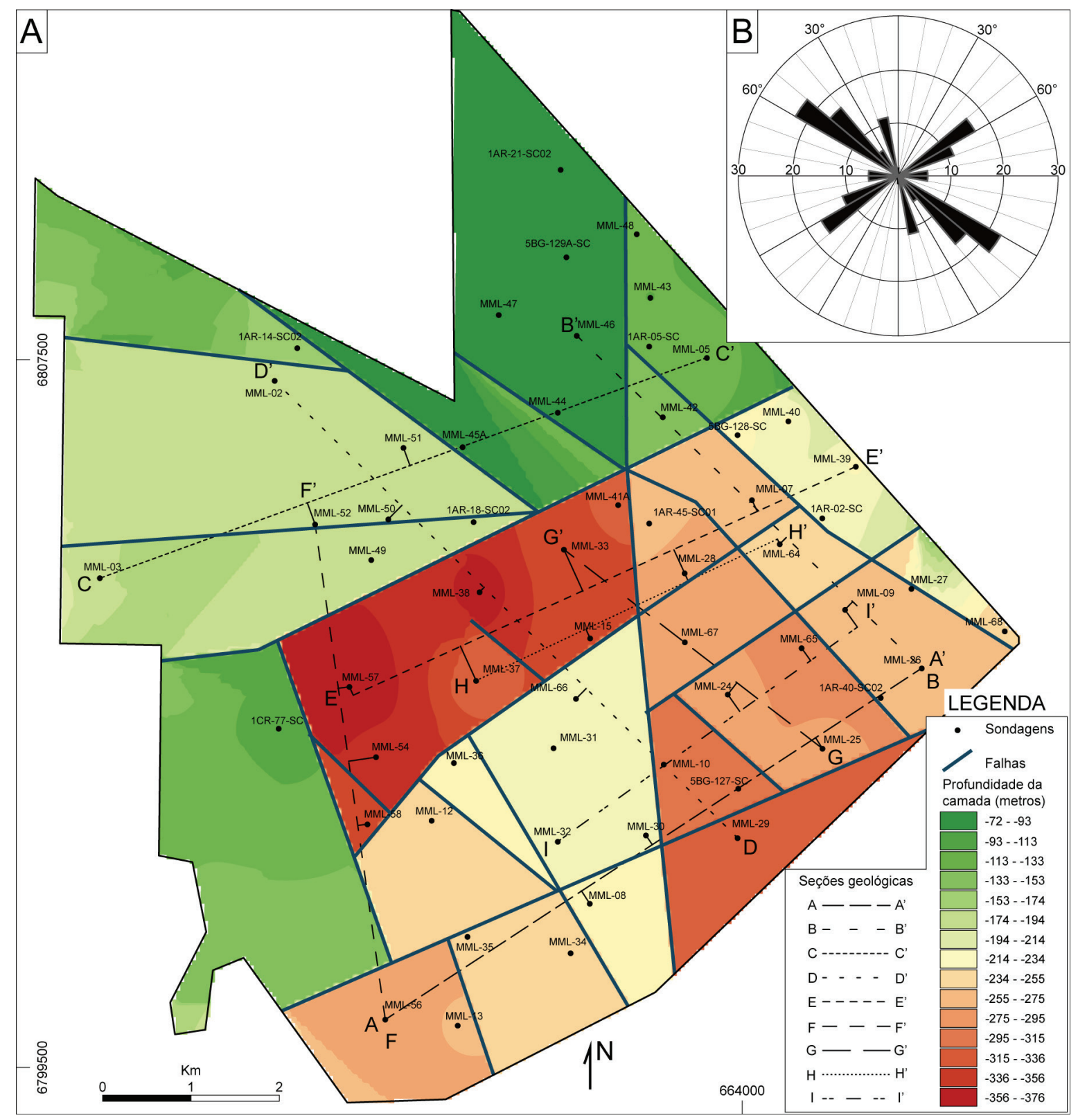

Figura 7. Interpretação estrutural da área de pesquisa. A) Mapa de contorno estrutural da camada de carvão Barro Branco com as falhas; B) Diagrama de Roseta de frequência acumulada das falhas na área.

Figure 7. Structural interpretation of the research area. A) Barro Branco coal seam structural contour map with faults; B) Rose Diagram of accumulated frequency of the faults in the area. 
selecionadas são apresentadas nas figuras 8 e 9 . As falhas representam as principais feições estruturais identificadas na área e apresentam as direções $\mathrm{N} 30^{\circ}-60^{\circ} \mathrm{W}, \mathrm{N} 50^{\circ}-70^{\circ} \mathrm{E}, \mathrm{N} 10^{\circ}-20^{\circ} \mathrm{W}$ e E-W (Fig. 7B). 0 cruzamento dos sistemas de falhas resulta em um mosaico irregular com blocos abatidos e soerguidos, ocasionando o afundamento da camada a partir da porção central em direção ao limite SE da área de pesquisa. Em toda a extensão da região carbonífera são descritos basculamentos de blocos que geram mergulhos suaves do acamadamento sedimentar para o quadrante SW. Devido ao limitado número de dados disponíveis para este trabalho, a interpretação do arcabouço estrutural da área da Mina D considera que as diferenças de cota da camada de carvão entre os furos de sondagem é ocasionada por falhas, principalmente quando a diferença de cota entre os furos é expressiva. Possivelmente ocorrem blocos basculados, sobretudo naqueles em que a diferença de cota da camada de carvão entre os furos não é tão expressiva e poderia ser interpretada como um mergulho suave. Porém, tal interpretação poderia induzir a um erro maior na estimativa do arcabouço estrutural da área, que tem por objetivo gerar um modelo simples baseado nos dados disponíveis e nas referências bibliográficas sobre a geologia estrutural da região carbonífera de Santa Catarina.

As falhas de direção $\mathrm{N} 30^{\circ}-60^{\circ} \mathrm{W}$ são as que ocorrem com maior frequência na área (Fig. 7B), seguidas por falhas de direção $\mathrm{N} 50^{\circ}-70^{\circ} \mathrm{E}$, que são as mais extensas. $\mathrm{O}$ rebaixamento da camada de carvão está relacionado com estas falhas, que também registram os rejeitos mais expressivos na área, atingindo mais de $100 \mathrm{~m}$ em alguns locais. A porção central da área de pesquisa constitui um baixo estrutural, caracterizando um graben delimitado por duas falhas de direção $\mathrm{N} 50^{\circ}-70^{\circ} \mathrm{E}$. $\mathrm{O}$ mapa de contorno estrutural mostra este rebaixamento da camada de carvão e a diferença da cota de lapa da camada entre o teto e o muro, que é de $180 \mathrm{~m}$. Este rejeito é resultante da soma dos rejeitos das falhas de direção $\mathrm{N} 50^{\circ}-70^{\circ} \mathrm{E}$ e $\mathrm{N} 10^{\circ}-20^{\circ} \mathrm{W}$, como mostram as seções E-E' (Fig. 8B) e D-D' (Fig. 9A). As falhas de direção NE, que delimitam o graben nas suas porções NW e SE, têm rejeitos da ordem de $110 \mathrm{~m}$. 0 rejeito da falha de direção $\mathrm{N} 10^{\circ}-20^{\circ} \mathrm{W}$ do limite NE é de aproximadamente $70 \mathrm{~m}$. Em relação à falha que delimita a estrutura a SW não se pode afirmar o rejeito, pois o perfil litológico do único furo de sondagem do bloco soerguido não está disponível. A falha de direção $\mathrm{N} 10^{\circ}-20^{\circ} \mathrm{W}$ que delimita o graben na sua extremidade NE apresenta um rejeito variável. Na porção norte da falha o teto se situa no lado oeste, enquanto na porção sul da falha, o teto se situa no lado leste (Fig. 7A).

Na porção norte da área, nos furos MML 44, 46 e 47, em que a cota da lapa da camada de carvão é da ordem de -80 m, a análise do mapa de contorno estrutural pode levar a interpretação de que o deslocamento do teto em relação ao muro, situado a leste e que abrange os furos MML 43, 48 e 05, é ocasionado pelo rejeito de uma falha. É interpretada a ocorrência de uma falha entre os blocos, como mostra a seção B-B' (Fig. 9B), porém o soerguimento do teto está relacionado à intrusão de uma soleira de diabásio. Subtraindo-se a espessura do corpo de diabásio (85 m) dos perfis dos furos, a cota da camada no teto estaria $20 \mathrm{~m}$ abaixo da cota da camada no muro. Outra porção com soerguimento da camada de carvão devido à intrusão de uma soleira de diabásio se situa na parte central da área de pesquisa, mais precisamente entre os furos MML 08, 30 e 32. Entre estes furos ocorre uma falha de direção $\mathrm{N} 50^{\circ}-70^{\circ} \mathrm{E}$ que desloca a soleira de diabásio, ou seja, a movimentação da falha é posterior a sua intrusão, como mostra a seção A-A' (Fig. 8A). 0 soerguimento da camada de carvão por soleiras de diabásio ocorre quando estas se posicionam no intervalo estratigráfico da Formação Rio Bonito, abaixo da camada de carvão Barro Branco. Este fato é identificado nas seções geológicas ou verificando-se a espessura do intervalo estratigráfico entre as camadas de carvão Barro Branco e Bonito Inferior.

As soleiras de diabásio, cuja presença é expressiva na área, se mostraram bons guias na análise estrutural. Uma grande soleira ocorre no intervalo estratigráfico da Formação Irati e abrange as porções central e leste da área de pesquisa, sendo identificada em todas as seções apresentadas (Figs. 8 e 9). Os corpos de diabásio auxiliaram na interpretação das seções geológicas por evidenciarem as falhas que sofreram deslocamento após a sua intrusão nas rochas sedimentares. Aquelas falhas que deslocam as rochas sedimentares, mas 


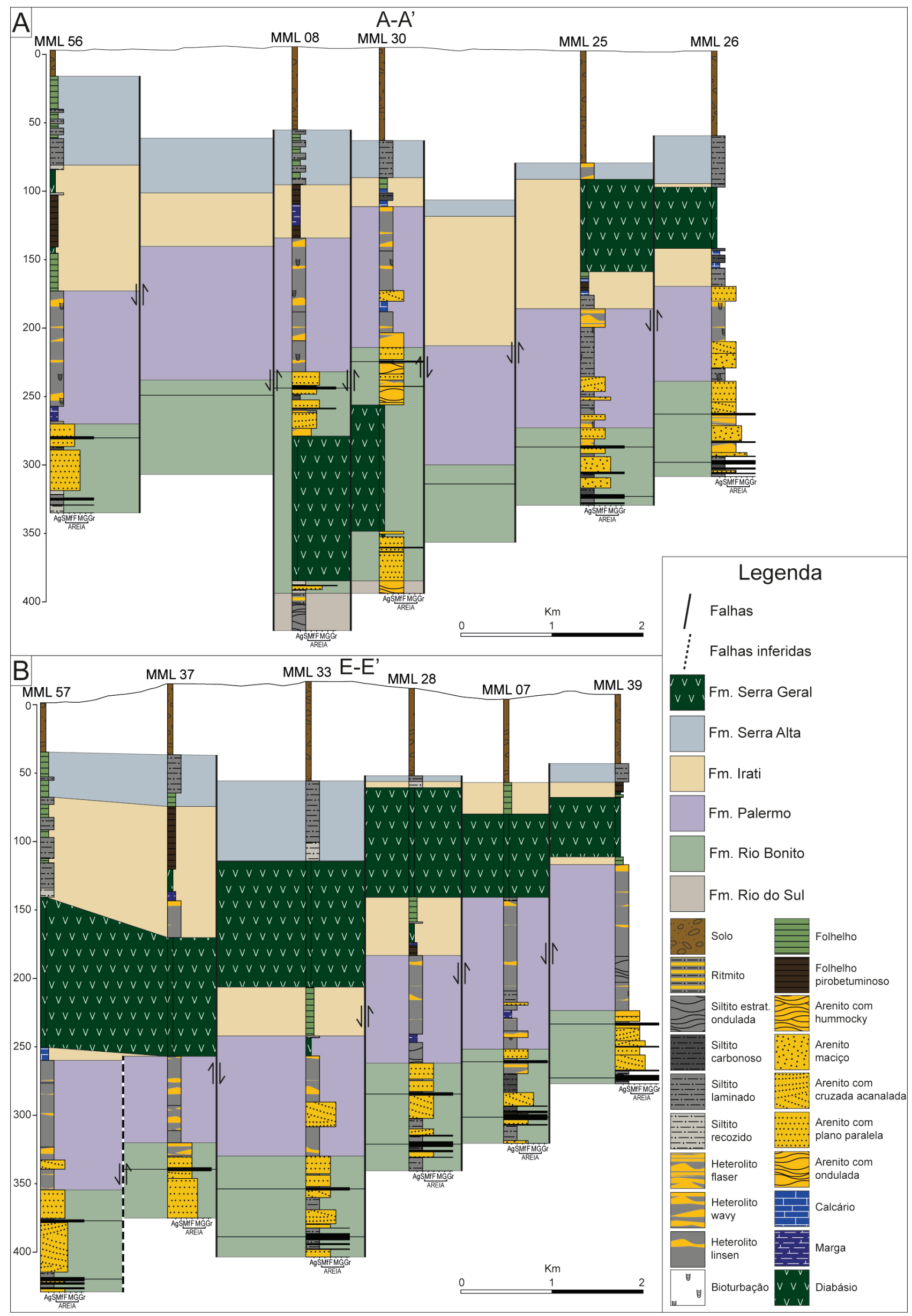

Figura 8. Seções geológicas de direção NE-SW. A) Seção A-A'; B) Seção E-E'.

Figure 8. Geological sections of NE-SW direction. A) A-A' section; B) E-E' section. 


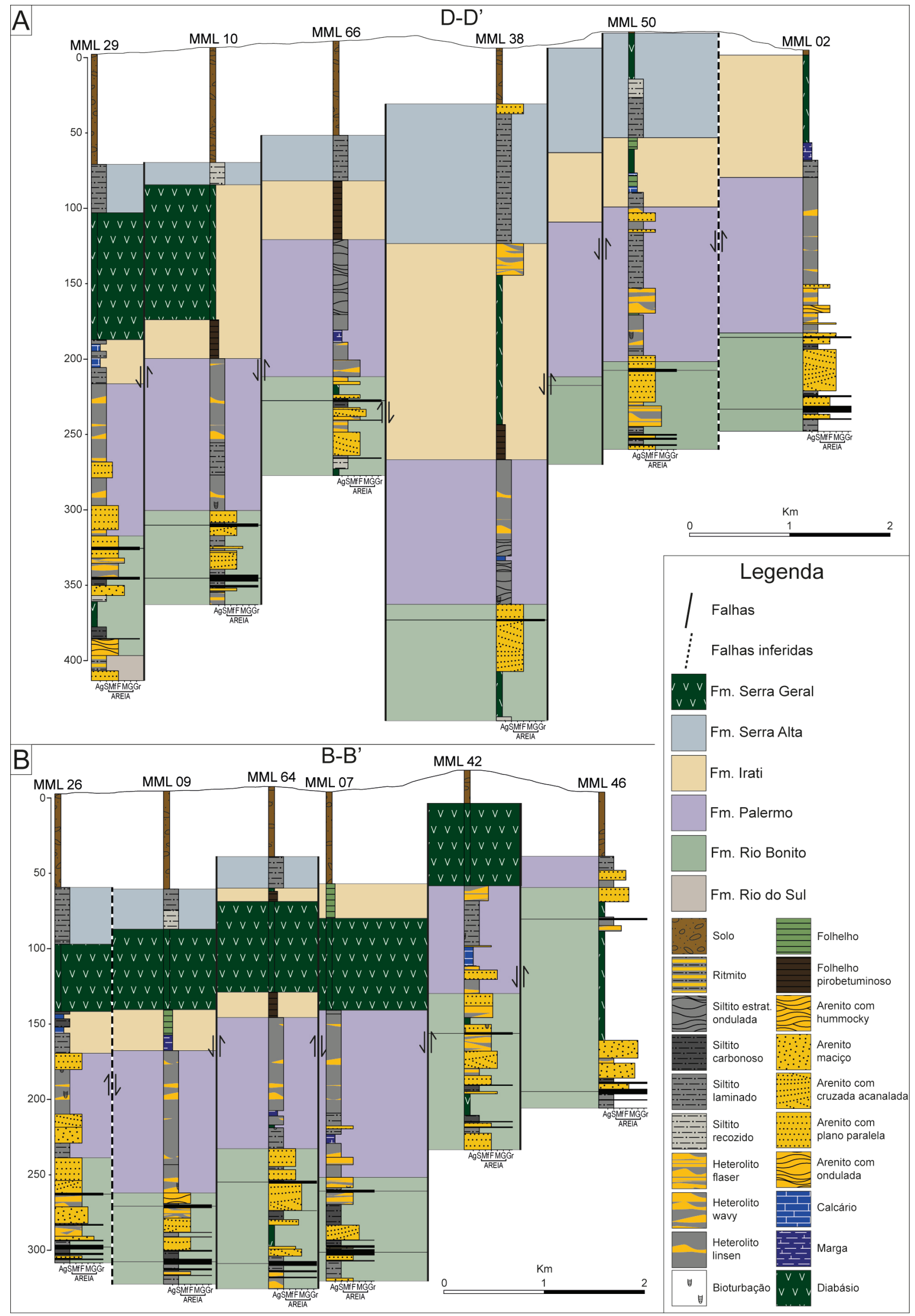

Figura 9. Seções geológicas de direção NW-SE. A) Seção D-D’; B) Seção B-B'.

Figure 9. Geological sections of NW-SE direction. A) $D$ - $D^{\prime}$ section; $B$ ) $B$ - $B$ ' section. 
não deslocam as soleiras de diabásio, foram formadas anteriormente a sua intrusão. Entre os furos MML 45A e MML 44, ocorre uma soleira de diabásio que intrude a Formação Rio Bonito na mesma cota, porém em intervalos estratigráficos diferentes. Essa relação sugere a existência de uma falha anterior à intrusão do diabásio. Na seção E-E' (Fig. 8B) é possível observar que entre os furos MML 57, 37 e 33 a soleira de diabásio indica que o perfil do furo MML 37 está no teto da falha e foi rebaixado em relação aos adjacentes, enquanto que a camada de carvão Barro Branco indica que o mesmo perfil está no muro da falha e foi soerguido. Este comportamento sugere a presença de falhas anteriores a intrusão do diabásio, que soergueram o perfil MML 37 em relação aos outros perfis, e de falhas posteriores a sua colocação, responsáveis pelo abatimento dos blocos em que se situam os furos MML 57, 37 e 33 (Fig. 8B).

As seções geológicas realizadas não mostram uma relação entre as falhas estimadas na área e variações na espessura do intervalo estratigráfico da Formação Rio Bonito. A seção E-E' evidencia uma falha que desloca apenas as Formações Rio Bonito e Palermo, que deve se tratar de uma falha sin-sedimentar formada antes da deposição da Formação Irati. 0 mapa de contorno estrutural foi comparado com um mapa de isópacas da camada e com um mapa de espessura de carvão na camada Barro Branco. Não foi identificada correlação entre as estruturas estimadas na área e a espessura da camada de carvão. Ocorre um discreto aumento da espessura na camada de carvão situada no baixo estrutural da parte central da área de pesquisa, que pode ser relacionado às estruturas que geraram o graben.

\section{Discussões}

Em zonas de falhas, a trama estrutural da rocha exerce grande impacto na estabilidade das escavações, sendo esse aspecto do maciço rochoso muitas vezes negligenciado (Phillipson, 2005a, 2005b). Diversos trabalhos acerca da caracterização estrutural em regiões de mineração de carvão são encontrados na literatura, em grande parte realizados durante as atividades de mineração, onde a determinação das estruturas é feita in situ e a sua influência na estabilidade das escavações é visível (Coolen, 2003; Bailey et al., 2005; Phillipson, 2005a, 2005b). 0 deslocamento vertical da camada de carvão por zonas de falhas é um dos principais problemas a ser considerado em áreas afetadas por atividades tectônicas. Em alguns casos a camada é deslocada por dezenas de metros, o que exige adaptações no projeto da mina. Muitas vezes além do rejeito vertical, as falhas ocasionam o basculamento da camada de carvão, o que praticamente inviabiliza a mineração em áreas com mergulho superior a 15을 (Nelson, 1991).

A descrição geotécnica das descontinuidades é de grande importância na identificação de áreas de risco em minas subterrâneas. As características a serem observadas são a orientação, espaçamento, persistência, abertura, rugosidade e preenchimento (ISRM, 1978). A diminuição na estabilidade do teto das galerias é outro fator relacionado à presença de falhas e zonas fraturadas. A configuração das galerias e dos pilares deve considerar a orientação e o espaçamento das descontinuidades. As zonas de falhas compostas por famílias de fraturas pouco espaçadas, ou famílias que se intersectam, são ligadas a zonas de instabilidade nas minas, uma vez que provocam intensa fragmentação da rocha e catalisam os processos de alteração intempérica (Nelson, 1991). Galerias que avançam de modo paralelo à direção das falhas e dos principais sistemas de fraturas que se intersectam em forma de cunha, apresentam os maiores riscos de queda de teto. Nesses casos a melhor orientação das galerias é perpendicular ao seu plano, restringindo assim, a área de influência da zona de falha, o volume de material estéril escavado e a área com suporte de teto complementar. Além da complementação do sistema de suporte de teto é comum a necessidade de adaptar o tamanho dos pilares nas proximidades da zona de falha. 0 influxo de água por zonas de falhas pode acelerar a alteração da rocha e trazer impurezas como argilas para o carvão, além de ocasionar problemas operacionais. Algumas falhas são caminhos de fluxo para água subterrânea, enquanto outras são barreiras para o movimento da água (Nelson, 1991). A ascensão de diques de diabásio, frequentemente é associada à ocorrência de zonas de falhas e pode trazer problemas para a mineração 
de carvão. Os diques de diabásio que ocorrem em toda a região carbonífera de Santa Catarina, além de constituir um material estéril a ser removido, são rochas duras que impõe muito desgaste aos equipamentos utilizados na mineração. Os principais tipos de falhas relacionados a problemas de instabilidade do teto são as falhas normais oblíquas e falhas de rejeito direcional, enquanto as falhas normais não aparentam ter essa associação (Peng, 1986). Falhas inversas também representam zonas de instabilidade de teto por concentrarem esforços compressionais (Krebs, 2004; Brady \& Brown, 2005).

A interpretação estrutural através de imagens de satélite se mostrou uma ferramenta útil na identificação das principais feições estruturais da região. A análise dos lineamentos apresentou resultados semelhantes aos descritos anteriormente em trabalhos realizados na região carbonífera de Santa Catarina (Tab. 1) (Fabrício et al., 1973; Krebs et al., 1982; Krebs, 2004). As direções dos lineamentos encontradas neste trabalho são compatíveis com as apresentadas por Krebs (2004). As variações dos resultados apresentados nos dois trabalhos são atribuídas às diferentes metodologias utilizadas.

As zonas de falhas identificadas neste trabalho e interpretadas como sendo as mais antigas têm direções $\mathrm{N} 10^{\circ}-30^{\circ} \mathrm{W}$ e $\mathrm{N} 30^{\circ}-60^{\circ} \mathrm{W}$. Estes sistemas de falhas são predominantes nas rochas do embasamento pré-cambriano (Fig. 6C) e nas rochas sedimentares da Bacia do Paraná (Fig. 6D). Estas estruturas apresentam relação com a formação de calhas estruturais e altos do embasamento, áreas onde pode haver maior acumulação de carvão, erosão ou não deposição (Fabrício et al., $1972 b ;$ Krebs, 2004). Este fato associado às variações de espessura da Formação Rio Bonito sugere que os sistemas de falhas foram ativos durante a sedimentação. 0 comprimento máximo para os lineamentos destes sistemas encontrado neste trabalho é de $17 \mathrm{~km}$, porém é descrita a ocorrência de uma falha pertencente ao sistema $\mathrm{N} 10^{\circ}-30^{\circ} \mathrm{W}$ com mais de $50 \mathrm{~km}$ de extensão que cruza a região carbonífera e se estende no Planalto da Serra Geral (Krebs, 2004). Os sistemas de falhas de direção NW-SE são identificados no Rio Grande do Sul e condicionaram a formação e o soerguimento do Arco de Rio Grande e a deposição das unidades da Formação Santa Maria de idade triássica (Faccini, 2000, 2007; Zerfass et al., 2003, 2005; Philipp et al., 2013a, 2013b, 2014) e também das unidades sedimentares da Formação Guará e do arenito Pedreira no início do Jurássico (Scherer \& Lavina, 2006; Brückmann et al., 2016). O Arco de Rio Grande é sucedido ao nordeste pela Sinclinal de Torres, estrutura que se estende até próximo da região de Araranguá e que condicionou grande parte do vulcanismo fissural da Formação Serra Geral no nordeste do estado do Rio Grande do Sul e sul de Santa

Tabela 1. Tabela com as direções de lineamentos obtidas por diferentes autores na Bacia do Paraná. Table 1. Table with the lineaments directions obtained from different authors in the Paraná Basin.

\begin{tabular}{|c|c|c|}
\hline Direções dos lineamentos & Região & Referência \\
\hline $\mathrm{N} 30^{\circ}-60^{\circ} \mathrm{W}, \mathrm{N} 45^{\circ}-60^{\circ} \mathrm{E}, \mathrm{E}-\mathrm{W}, \mathrm{N}-\mathrm{S}$ & $\begin{array}{l}\text { Região carbonífera de Santa } \\
\text { Catarina }\end{array}$ & Krebs et al., 1981, 1982 \\
\hline $\mathrm{N} 45^{\circ}-65^{\circ} \mathrm{W}, \mathrm{N} 50^{\circ}-70^{\circ} \mathrm{E}, \mathrm{E}-\mathrm{W}$ & Bacia do Paraná & Zalán et al., 1987 \\
\hline $\begin{array}{l}\text { No5 } 5^{\circ}-30^{\circ} \mathrm{W}, \mathrm{N} 45^{\circ}-75^{\circ} \mathrm{E}, \mathrm{N}-\mathrm{S}, \\
\text { N30 }\end{array}$ & $\begin{array}{l}\text { Bacia hidrográfica do Rio } \\
\text { Araranguá (SC) }\end{array}$ & Krebs, 2004 \\
\hline $\mathrm{N}-\mathrm{S}, \mathrm{N} 65^{\circ} \mathrm{E}, \mathrm{N} 45^{\circ} \mathrm{E}, \mathrm{N} 45^{\circ} \mathrm{W}, \mathrm{NNE}$ & $\begin{array}{l}\text { Borda leste da Bacia do Paraná } \\
\text { (SC) }\end{array}$ & Jacques et al., 2010 \\
\hline $\begin{array}{c}\mathrm{N} 60^{\circ}-70^{\circ} \mathrm{E}, \mathrm{N}^{\circ} 0^{\circ}-30^{\circ} \mathrm{E}, \mathrm{N}^{\circ} 5^{\circ}-30^{\circ} \mathrm{W} \\
\mathrm{N} 40^{\circ}-50^{\circ} \mathrm{W}\end{array}$ & Domo de Lages & Roldan et al., 2010 \\
\hline $\begin{array}{c}\mathrm{N} 30^{\circ}-60^{\circ} \mathrm{W}, \mathrm{N} 60^{\circ}-80^{\circ} \mathrm{E} \\
\mathrm{N} 30^{\circ}-60^{\circ} \mathrm{E}, \mathrm{N} 60^{\circ}-80^{\circ} \mathrm{W} \\
\mathrm{N} 10^{\circ}-30^{\circ} \mathrm{E}, \mathrm{N} 10^{\circ}-30^{\circ} \mathrm{W}, \mathrm{N}-\mathrm{S}, \mathrm{E}-\mathrm{W}\end{array}$ & $\begin{array}{l}\text { Região carbonífera de Santa } \\
\text { Catarina }\end{array}$ & Este trabalho \\
\hline
\end{tabular}


Catarina (Stica et al., 2014; Waichel et al., 2012). A região onde está situada a Mina D faz parte de uma estrutura soerguida referida aqui como Arco de Lages. Trabalhos anteriores como os de Northfleet et al., (1969), Almeida (1983) e Roldan (2007) descreveram esta estrutura de direção NW-SE e o soerguimento da região.

Os lineamentos de direção $N 60^{\circ}-80^{\circ} \mathrm{E}$ ocorrem em toda a região carbonífera e são predominantes na Formação Serra Geral (Fig. 6F). Este sistema de falhas são as maiores estruturas da região e intersectam as falhas de direções $\mathrm{N} 10^{\circ}$ $-30^{\circ} \mathrm{W}$ e $\mathrm{N} 30^{\circ}-60^{\circ} \mathrm{W}$ (Fabrício et al., 1973; Krebs et al., 1982; Krebs, 2004). A formação destas falhas de direção NE-SW é atribuída aos processos extensionais envolvidos na separação continental e abertura do Oceano Atlântico (Almeida, 1967, 1969, 1980, 1981). A influência destas falhas na região é marcante, visto que a camada de carvão Barro Branco ocorre na cota de 350 m na porção NW da região carbonífera, enquanto na área da mina, na porção SE, atinge a cota dos $-350 \mathrm{~m}$ de profundidade (Fig 4B). Este conjunto de falhas de direção NE define para a região carbonífera de Santa Catarina uma estruturação associada a uma bacia de rift de meio graben com um deslocamento inferido mínimo de $700 \mathrm{~m}$. Esta estrutura afeta as soleiras de diabásio da Formação Serra Geral e representa a evolução inicial do rift e o preenchimento da porção norte da Bacia de Pelotas (Stica et al., 2014). Estes autores demonstraram por sísmica regional profunda que as falhas normais da borda continental (proximal domain) da porção norte da Bacia de Pelotas possuem direção nordeste com mergulhos elevados para noroeste.

Os lineamentos de direção $\mathrm{N} 10^{\circ}-30^{\circ} \mathrm{E}$ e $\mathrm{N}-\mathrm{S}$ ocorrem de maneira subordinada na região, porém em alguns casos, apresentam grande extensão. Estas falhas, geralmente encaixam diques de diabásio (Florisbal et al., 2014; Krebs, 2004) e por isso tem grande importância para a mineração. Stica et al. (2014) identificaram anomalias magnéticas circulares alongadas ao longo de um trend de direção N-S paralelo a costa do estado de Santa Catarina, interpretando estas estruturas como falhas extensionais.

Os lineamentos de direção E-W são pouco representativos, mas registram as atividades re- centes de movimentação das zonas de fraturas Florianópolis e Rio Grande (Stica et al., 2014). Estas estruturas estão relacionadas à expansão da Dorsal do Meso-Atlântico e representam o limite ainda indefinido entre as bacias de Pelotas e Santos.

As direções dos lineamentos identificadas nas imagens de satélite e as direções das falhas estimadas com a interpretação do mapa de contorno estrutural da camada de carvão Barro Branco e das seções geológicas na área da Mina D são condizentes. As falhas identificadas na área de pesquisa têm direções principais $\mathrm{N} 30^{\circ}-60^{\circ} \mathrm{W}$ e $\mathrm{N} 50^{\circ}-70^{\circ} \mathrm{E}$, idênticas às descritas em outras áreas da região carbonífera por Krebs et al. (1982, 1983). De forma subordinada, ocorrem falhas de direção $\mathrm{N} 10^{\circ}-20^{\circ} \mathrm{W}$ e E-W. As falhas que ocorrem na região carbonífera são, predominantemente, falhas normais com disposição subvertical a vertical (Fabrício et al., 1972b, 1973). A feição estrutural mais marcante na área é o rebaixamento gradativo da camada de carvão em direção à linha de costa, comportamento relacionado às falhas de direção $\mathrm{N} 50^{\circ}-70^{\circ} \mathrm{E}$. Este sistema de falhas é considerado o mais importante na área por ser o mais influente no seu arcabouço estrutural. Tais rejeitos podem ser relacionados a uma falha, ou serem resultado da soma do rejeito de sucessivas falhas menores. Estas falhas são extensas e contínuas e duas delas cortam a área de pesquisa e se estendem para fora dela, o que sugere que são falhas regionais. Provavelmente uma destas falhas é continuação da Falha das Lagoas (Fabrício et al., 1973), a qual se estende por $30 \mathrm{~km}$ do sul de Araranguá até Balneário Rincão e apresenta rejeito variando de 30 a 110 m. Estes rejeitos impedem que a mineração atravesse a zona de falha e com isso as galerias devem avançar em direção paralela à falha. A estrutura do tipo graben na porção central da área de pesquisa apresenta deslocamento vertical de aproximadamente $180 \mathrm{~m}$, sendo resultado da soma dos rejeitos das falhas $\mathrm{N} 50^{\circ}-70^{\circ} \mathrm{E}$ e $\mathrm{N} 10^{\circ}-20^{\circ} \mathrm{W}$ que o delimitam. As seções geológicas mostram que o maior deslocamento é atribuído a falha de direção $N 50^{\circ}-70^{\circ} \mathrm{E}$ que atravessa a área de pesquisa e limita o graben na sua porção NW. Esta falha rebaixa todo o bloco situado ao SE da estrutura produzindo um rejeito vertical de $110 \mathrm{~m}$. 0 rebaixamento deste bloco inviabiliza a recuperação do carvão nesta área. Esse 
comportamento estrutural de rebaixamento gradativo da camada de carvão em direção ao litoral (Fabrício et al., 1973; Krebs, 2004) é relacionado ao rifteamento ocorrido no Cretáceo (Gonçalves et al., 1979; Krebs, 2004). As falhas que controlam este rebaixamento possuem direção similar às falhas identificadas na região de Araranguá e ocorrem desde a porção NW da região carbonífera, com rejeitos de até $30 \mathrm{~m}$ (Krebs et al., 1982, 1983), até a porção SE da região, onde atingem rejeitos superiores a 100 m (Fabrício et al., 1973; Krebs, 2004). 0 sistema de falhas de direção $\mathrm{N} 30^{\circ}-60^{\circ} \mathrm{W}$ é o mais frequente na área de pesquisa e na região carbonífera, sendo considerado o sistema de falhas mais antigo na região, pois controla a formação de calhas tectônicas de maior acumulação de carvão e altos do embasamento (Fabrício et al., 1972b; Krebs, 2004). Foi identificado nas seções geológicas que este sistema de falhas apresenta movimento vertical e por vezes desloca apenas as formações Rio Bonito e Palermo. Estas falhas são sin-sedimentares e anteriores a implantação do magmatismo da Formação Serra Geral e da intrusão de soleiras de diabásio. 0 rejeito máximo para as falhas deste sistema identificadas na área é de 30 m, compatível com o que é identificado nas outras áreas. A variação do rejeito em falhas pertencentes a este sistema foi reconhecida anteriormente por Krebs et al. (1982, 1983), sugerindo que as mesmas podem ocorrer como falhas em tesoura, fato não identificado na área de Mina D. Este sistema de falhas deve ser mapeado com maior atenção na área. Por apresentar falhas de menor extensão e de pequenos rejeitos sua presença não é tão evidente e devem ocorrer falhas deste sistema que não foram identificadas neste trabalho. Em relação às falhas com rejeito e extensão de maior expressão, as galerias devem avançar de modo paralelo, ou devem cruzá-las com disposição perpendicular. Krebs (2004) descreve na região da bacia hidrográfica do Rio Araranguá a ocorrência de um sistema de falhas de menor expressão com direção $\mathrm{N} 30^{\circ}-45^{\circ} \mathrm{W}$, resultante da reativação de sistemas mais antigos, que secciona as falhas do sistema NE. As falhas de direção $\mathrm{N} 10^{\circ}-20^{\circ} \mathrm{W}$ definidas na área da mina são correlacionadas ao sistema N-S identificado em outros trabalhos. Apesar de serem menos frequentes, são falhas de grande extensão e que podem apresentar rejeitos da ordem de $100 \mathrm{~m}$ (Fabrício et al., 1973). A falha deste sistema que delimita o graben na sua porção NE se estende além da área de pesquisa e apresenta rejeito de $70 \mathrm{~m}$. As falhas com esta direção têm caráter extensional e geralmente encaixam diques de diabásio (Krebs, 2004). É reportada a ocorrência localizada de falhas inversas associadas às intrusões de diabásio na região (Fabrício et al., 1972b, Zalán et al., 1987; Krebs, 2004). Este condicionamento é encontrado na área de pesquisa, onde uma mesma falha comporta-se como falha normal no intervalo da camada de carvão Bonito Inferior e como falha inversa no intervalo da camada de carvão Barro Branco, relacionado ao soerguimento gerado por uma soleira de diabásio intrudida no intervalo entre as duas camadas. Estas áreas de soerguimento de blocos associados às intrusões de diabásio são áreas de acúmulo de tensões compressivas, por isso a mineração próxima a soleiras deve ser evitada. Falhas de extensão local e pequenos rejeitos $(<5 \mathrm{~m})$, ou até inexistentes, são provavelmente as que mais serão encontradas na mineração de carvão (Fabrício et al., 1972a), visto que com a interpretação estrutural da área as zonas de falha mais extensas e com rejeitos expressivos foram estimadas e devem ser evitadas. Observar as características geotécnicas destas falhas e dos sistemas de fraturas associados é importante para definir os melhores métodos de estabilização em cada caso. Falhas com estas características dificilmente serão definidas no trabalho de pesquisa com a metodologia aplicada neste trabalho, porém a estimativa das zonas de falha e suas direções é imprescindível.

As idades relativas dos processos que geraram os sistemas de falhas rúpteis descritos neste trabalho podem ser estabelecidas a partir de relações de campo e das relações obtidas nas seções geológicas. Adicionalmente, para esta região de Santa Catarina, existem informações termocronológicas obtidas a partir de idades de traços de fissão em apatita e zircão (Gallagher et al., 1995; Jelinek, 1997; Karl et al., 2013). Os dados de traços de fissão obtidos por estes autores indicam que a evolução tectônica da margem passiva do Atlântico Sul na região sul envolveu quatro eventos tectônicos principais: (i) Fase Pré-Rift (155-135 Ma), (ii) 1 Pulso Fase Rift (135-113 Ma), (iii) 2 Pulso 
Fase Rift (113-90 Ma) e (iv) Fase Pós-Rift (90-66 $\mathrm{Ma}$ ), marcada pelo soerguimento (Arco de Lages) e rebaixamento regional (Graben de Urussanga).

0 primeiro evento está associado às atividades termais anteriores a instalação da Pluma de Tristão da Cunha na base da Crosta (Bueno, 2004; Waichel et al., 2012). 0 segundo evento marca o pico térmico $(\sim 130 \mathrm{Ma})$ associado com a abertura do Gondwana e com a movimentação de falhas normais de direção NW-SE, que atuaram como condutos principais para a extrusão das lavas da Formação Serra Geral e que estão registradas nos enxames de diques e soleiras de diabásio dos arcos de Ponta Grossa e Rio Grande e no Sinclinal de Torres. Bueno (2004) sugere uma mudança na direção dos enxames de diques de ortogonais ao Rift do Atlântico Sul, entre 133 e 130 Ma, para diques paralelos ao rift, entre 130 e 125 Ma. Esta mudança está associada à geração de uma discordância regional nas bacias de Santos (Bueno, 2004) e de Pelotas (Stica et al., 2014) e a rotação dos Seaward Dipping Reflectors (SDR), observados a partir de seções sísmicas profundas. Este período estaria associado à geração das falhas de direção N50-70E. A movimentação destas falhas ainda se estenderia ao terceiro evento tectônico e seria responsável pela deformação dos sedimentos sin-rift e pela geração dos rejeitos observados nos sistemas de falhas NE que afetaram a área da Mina D. 0 último evento tectônico, com pulso principal entre 90 e 66 Ma está associado ao soerguimento regional dos arcos de Rio Grande, Ponta Grossa e de Lages e ao rebaixamento e formação do Sinclinal de Torres e do Graben de Urussanga, situados respectivamente, ao sul e ao norte da área de estudo.

\section{Conclusões}

Este trabalho estimou os sistemas de falhas existentes na área de pesquisa da Mina D e identificou as suas características geológicas principais a partir da integração de observações realizadas por outros autores em diferentes locais da região carbonífera e dos dados avaliados nesta pesquisa. A análise dos lineamentos por imagens de satélite se mostrou uma ferramenta eficiente na estimativa dos principais sistemas de falha da região. A região é amplamente afetada por sistemas de falhas de direções $\mathrm{N} 30^{\circ}-60^{\circ} \mathrm{W}, \mathrm{N} 60^{\circ}-80^{\circ} \mathrm{E}, \mathrm{N} 30^{\circ}-60^{\circ} \mathrm{E}, \mathrm{N} 10^{\circ}$ $-30^{\circ} \mathrm{W}$ e de modo subordinado, por sistemas de orientação $\mathrm{N} 60^{\circ}-80^{\circ} \mathrm{W}, \mathrm{N} 10^{\circ}-30^{\circ} \mathrm{E}, \mathrm{N}-\mathrm{S}$ e E-W.

A interpretação do mapa de contorno estrutural da camada de carvão e das seções geológicas mostrou o arcabouço estrutural e as principais direções de falhas da área. Os principais sistemas de falhas da área apresentam direção $\mathrm{N} 30^{\circ}-60^{\circ} \mathrm{W}$ e $\mathrm{N} 50^{\circ}-70^{\circ} \mathrm{E}$, com sistemas subordinados de direção $\mathrm{N} 10^{\circ}-20^{\circ} \mathrm{W}$ e E-W. As falhas que mais influenciam no arranjo estrutural da área são as de direção $\mathrm{N} 50^{\circ}-70^{\circ} \mathrm{E}$, que apresentam extensão regional e rejeitos que podem ser superiores a $100 \mathrm{~m}$. Por estas características é um sistema que deve condicionar a orientação das galerias da mina, com a frente de lavra avançando paralela a esta direção nas proximidades destas falhas. Em algumas porções da área, como no graben localizado na parte central da área, o deslocamento vertical associado a estas falhas inviabiliza técnica e economicamente a extração do carvão. As falhas de direção $\mathrm{N} 30^{\circ}-60^{\circ} \mathrm{W}$ são as mais frequentes na área, consequentemente é o sistema que mais deverá influenciar na mineração de carvão na área da Mina $\mathrm{D}$. As falhas deste sistema que apresentam maiores extensões e rejeitos devem ser consideradas no planejamento da lavra, a fim de evitar que tenham que ser cruzadas. Diques de diabásio podem estar associados a qualquer um dos sistemas de falha identificados, porém ocorrem com maior frequência nos sistemas de falhas de direções NW e N-S. As falhas inversas relacionadas às intrusões de diabásio podem gerar zonas de acúmulo de tensões, o que pode levar a problemas de estabilidade de teto $\mathrm{e}$ levantamento de piso. São escassas informações sobre as características geotécnicas dos sistemas de falhas e fraturas da região. 0 conhecimento destes aspectos é de grande auxílio para a mineração subterrânea de carvão.

Agradecimentos. RPP agradece ao CNPq pela concessão de bolsa de produtividade em pesquisa. Os autores agradecem a empresa Maracajá Mineração S.A. pela disponibilização dos dados para o trabalho e aos revisores pelas contribuições ao trabalho. 


\section{Referências bibliográficas}

Aboarrage, A. M. \& Lopes, R. da C. 1986. Projeto A Borda Leste da Bacia do Paraná: integração geológica e avaliação econômica. Porto Alegre: DNPM/CPRM, v. 18, 223p.

Almeida, F.F.M. 1967. Origem e evolução da plataforma brasileira. DNPM-DGM, Boletim 241, Rio de Janeiro, p.1-36.

Almeida, F.F.M. 1969. Diferenciação tectônica da plataforma brasileira. In: CONGRESSO BRASILEIRO DE GEOLOGIA, 23, SBG, Salvador, Anais, p. 29-46.

Almeida, F.F.M. 1980. Tectônica da Bacia do Paraná no Brasil. Relatório PAULIPETRO, São Paulo, IPI, p.1-18.

Almeida, F.F.M. 1981. Síntese sobre a tectônica da Bacia do Paraná. In: SIMPÓSIO REGIONAL DE GEOLOGIA, III, SBG-SP, Curitiba, Atas, v. 1, p. 1-20.

Almeida, F.F.M. 1983. Relações tectônicas das rochas alcalinas Mesozóicas da região meridional da Plataforma Sul-Americana. Revista Brasileira de Geociências, 13(3):139-158.

Bailey, W.R., Walsh, J.J. \& Manzocchi, T. 2005. Fault populations, strain distribution and basement fault reactivation in the East Pennines Coalfield, UK. Journal of Structural Geology, 27:913-928.

Bitencourt, M.F., Bongiolo, E.M., Philipp, R.P., Morales, L.F.G., Rubert, R.R., Melo, C.L. \& Luft Jr., J.L. 2008. Estratigrafia do Batólito Florianópolis, Cinturão Dom Feliciano, na região de Garopaba-Paulo Lopes, SC. Pesquisas em Geociências, 35(1):109-136.

Brady, B.H.G \& Brown, E.T. 2005. Rock Mechanics for underground mining. Netherlands, Springer, $628 p$.

Brückmann, M.P., Philipp, R.P., Scherer, C.M.S. \& Espindola, E. 2016. Petrografia e estratigrafia do Arenito Pedreira, Jurássico da Bacia do Paraná, RS. In: CONGRESSO BRASILEIRO DE GEOLOGIA, 48, Porto Alegre. Boletim de Resumos, SBG.

Bueno, G.V. 2004. Diacronismo de eventos no rifte Sul-Atlântico. Boletim de Geociências da Petrobras, 12(2):203-229.

Cardozo, N. \& Allmendinger, R.W. 2013. Spherical projections with OSXStereonet. Computers \& Geosciences. 51:193-205.
Caye, B.R., Pozza, E.V., Fabrício, J.A.C. \& Süffert, T. 1975. Projeto carvão no pré-Barro Branco. Porto Alegre: DNPM/CPRM, v. 1, 206p.

Coolen, J.M. 2003. Coal mining along the Warfield Fault, Mingo County, West Virginia: a tale of ups and downs. International Journal of Coal Geology, 54:193-207.

Fabrício, J.A.C., Silva, M.A.S. \& Valiati, D. 1972a. Projeto carvão de Santa Catarina: Estudos de geologia de subsuperfície. Porto Alegre: DNPM/ CPRM, v. 1, 106p.

Fabrício, J.A.C., Lange, F.M.Q., Valiati, D., Silva, M.A.S. \& Pozza, E.V. 1972b. Projeto carvão de Santa Catarina: relatório integrado. Porto Alegre: DNPM/CPRM, v. 1, 58p.

Fabrício, J.A.C., Aboarrage, A.M., Valiati, D., Pozza, E.V., Ferreira, J.A.F. \& Süffert, T. 1973. Projeto carvão de Santa Catarina: relatório integrado. Porto Alegre: DNPM/CPRM, v. 1, 203p.

Fabrício, J.A.C., Ferreira, J.A.F. \& Süffert, T. 1979. Projeto carvão em Araranguá-Torres: relatório final da $2^{a}$ etapa. Porto Alegre: DNPM/CPRM, v. $1,145 \mathrm{p}$.

Faccini, U.F. 2000. Estratigrafia do permo-triássico do Rio Grande do Sul: estilos deposicionais versus espaço de acomodação. Porto Alegre, 332p. Tese de Doutorado, Programa de Pós-graduação em Geociências, Instituto de Geociências, Universidade Federal do Rio Grande do Sul.

Faccini, U.F. 2007. Mesozoic sedimentary record of Southern Paraná Basin, Brazil. In: I WORKSHOP-PROBLEMS IN WESTERN GONDWANA GEOLOGY, 1., 2007, Gramado. Extended abstracts, (1): 42-45.

Ferreira, A.C. \& Almeida, T.I.R. 1989. Tectônica transcorrente e imagens TM-Landsat aplicadas à prospecção de fluorita e barita em Santa Catarina. Revista Brasileira de Geociências, 19(2):207-223.

Florisbal, L.M., Heaman, L.M., Janasi, V.A. \& Bitencourt, M.F. 2014. Tectonic significance of the Florianópolis Dyke Swarm, Paraná-Etendeka Magmatic Province: A reappraisal based on precise U-Pb dating. Journal of Volcanology and Geothermal Research, 289:140-150.

Gallagher, K., Hawkesworth, C.J. \& Mantovani, M.S.M. 1995. Denudation, fission track analysis and long-term evolution of passive margin 
topography: application to the southeast Brazilian margin. Journal of South American Earth Sciences, 8(1):65-77.

Gonçalves, A., Oliveira, M.A.M. \& Motta, S.O. 1979. A geologia da Bacia de Pelotas e da Plataforma de Florianópolis. Boletim Técnico da Petrobras, 22(3):157-174.

Holz, M. 1998. The Eo-Permian coal seams of the Paraná Basin in southernmost Brazil: analysis of the depositional conditions using sequence stratigraphy concepts. International Journal of Coal Geology, 36:141-163.

Holz, M., Kuchle, J., Philipp, R.P., Bischoff, A.P. \& Arima, N. 2006. Hierarchy of tectonic control on stratigraphic signatures: base-level changes during the Early Permian in the Paraná Basin, southernmost Brazil. Journal of South American Earth Sciences, 22:185-204.

ISRM. 1978. Suggested methods for the quantitative description of discontinuities in rock masses. International Journal of Rock Mechanics and Mining Sciences \& Geomechanics Abstracts, 15(6):319-368.

Jacques, P.D., Machado, R. \& Nummer, A.R. 2010. Lineamentos estruturais na borda leste da Bacia do Paraná em Santa Catarina: análise multiescala com base em imagens LANDSAT e SRTM. Pesquisas em Geociências, 37(2):117-131.

Jelinek, A.R. 1997. Análise por traços de fissão em apatitas (AFTA) da encaixante dos depósitos de fluorita filoniana do sudeste catarinense: uma evolução hidrotermal polifásica. Porto Alegre, 200 p. Dissertação de Mestrado, Programa de Pós-Graduação em Geociências, Instituto de Geociências, Universidade Federal do Rio Grande do Sul.

Jelinek, A.R., Bastos Neto, A.C., Leite, J.A.D., Hartmann, L.A. \& McNaughton, N.J. 2005. SHRIMP $\mathrm{U}-\mathrm{Pb}$ zircon dating of Pedras Grandes Suite, southern Santa Catarina State, Brazil. Anais da Academia Brasileira de Ciências, 77(1):125-135.

Kalkreuth, W., Holz, M., Mexias, A., Balbinot, M., Levandowski, J., Willett, J., Finkelman, R. \& Burger, H. 2010. Depositional setting, petrology and chemistry of Permian coals from the Paraná Basin: 2. South Santa Catarina Coalfield, Brazil. International Journal of Coal Geology, 84:213-236.

Karl, M., Glasmacher, U.A., Kollens, S., Stockli, D.F. \&
Hackspacher, P.C. 2013. Evolution of the South Atlantic passive continental margin in southern Brazil derived from zircon and apatite (U-Th -Sm)/He and fission track data. Tectonophysics, 604:224-244.

Krebs, A.S.J. 2004. Contribuição ao conhecimento dos recursos hídricos subterrâneos da bacia hidrográfica do Rio Araranguá, SC. Florianópolis, 375p. Tese de Doutorado, Curso de Doutorado em Geografia, Centro de Filosofia e Ciências Humanas, Universidade Federal de Santa Catarina.

Krebs, A.S.J., Grazia, C.A., Amaral, J.E., Casé, M.G., Branco, P. de M., Oliveira, R.L. \& Silva, V.R. 1982. Programa carvão energético no estado de Santa Catarina: relatório final. Porto Alegre: DNPM/ CPRM, v. 1, 206p.

Krebs, A.S.J., Grazia, C.A., Amaral, J.E., Casé, M.G., Oliveira, R.L. \& Silva, V.R. 1983. Projeto carvão nas áreas da mina Esperança e da mina Fontanella - SC: relatório final. Porto Alegre: DNPM/ CPRM, v. 1, 123p.

Lopes, R.C., Lavina, E.L. \& Signorelli, N. 1986. Fácies sedimentares e evolução paleoambiental do Supergrupo Tubarão na borda leste da Bacia do Paraná. Uma seção regional nos estados do Rio Grande do Sul e Santa Catarina. In: CONGRESSO BRASILEIRO DE GEOLOGIA, 34., 1986, Goiás. Anais... Goiás, SBG, v.1, p. 206-213.

Milani, E.J. 2004. Comentários sobre a origem e evolução tectônica da Bacia do Paraná. In: Mantesso-Neto, V., Bartorelli, A., Carneiro, C.D.R. \& Brito-Neves, B.B. de (Eds.). Geologia do continente Sul-Americano: Evolução da obra de Fernando Flávio Marques de Almeida. São Paulo, Beca, p. 265-279.

Milani, E.J. \& Ramos, V.A. 1998. Orogenias Paleozóicas no domínio sul-ocidental do Gondwana e os ciclos de subsidência da Bacia do Paraná. Revista Brasileira de Geociências, 28:473-484.

Milani, E.J., Melo, J.H.G., Souza, P.A., Fernandes, L.A. \& França, A.B. 2007. Bacia do Paraná. Boletim de Geociências da Petrobras, 15(2):265-287.

Nelson, W.J. 1991. Faults and their effect on coal mining in Illinois. Illinois State Geological Survey, Circular, 523:1-40.

Northfleet, A.A., Medeiros, R.A. \& Mülmann, H. 1969. Reavaliação dos dados geológicos da Bacia do Paraná. Boletim de Geociências da Petro- 
bras, 12(3): 291-346.

Peng, S. S. 1986. Coal Mine Ground Control. New Jersey, John Wiley \& Sons, 490p.

Philipp, R.P., Zvirtes, G., Brückmann, M.P., Faccini, U.F., Viana, A.R.,Lavina, E.\& Scherer, C.M.S. 2013a. Estruturas tectônicas na seção geológica Santana do Livramento-Rosário do Sul-Jaguari: evidências do Arco de Rio Grande, Bacia do Paraná, RS. In: SIMPÓSIO NACIONAL DE ESTUDOS TECTÔNICOS, 14., 2013, Chapada dos Guimarães. Boletim de Resumos Expandidos, Chapada dos Guimarães, SBG.

Philipp, R.P., Kloss, H.P., Schultz, C.L., Basei, M.A.S., Horn, B.L. \& Soares, M. 2013b. Proveniência por U-Pb LA-ICP-MS em zircão detrítico e idade de deposição da Formação Santa Maria, Triássico da Bacia do Paraná, RS: evidências da estruturação do Arco do Rio Grande. In: SIMPÓSIO NACIONAL DE ESTUDOS TECTÔNICOS, 14., 2013, Chapada dos Guimarães. Boletim de Resumos Expandidos, Chapada dos Guimarães, SBG.

Philipp, R.P., Rolim, S.B.A., Malta, L., Jelinek, A.R., Viana, A., Lavina, E.L., Cagliari, J. \& Faccini, U.F. 2014. Estruturação do Arco de Rio Grande e da Sinclinal de Torres, Bacia do Paraná, RS: evidências por levantamentos magnetotelúricos. In: SIMPÓSIO BRASILEIRO DE GEOFÍSICA, 6., 2014, Porto Alegre. Extended Abstracts, Porto Alegre, SBGf.

Phillipson, S.E. 2005a. Effects of late Paleozoic foreland deformation on underground coal mine ground instability, Illinois and Appalachian Basins. International Journal of Coal Geology, 64:319.

Phillipson, S.E. 2005b. Laramide orogeny-related controls on coal mine ground instability in Cretaceous coal seams, southern Rocky Mountain foreland. International Journal of Coal Geology, 64:20-43.

Queiroz, G.L., Salamuni, E. \& Nascimento, E.R. 2014. AzimuthFinder: ferramenta para a extração de dados e apoio na análise estrutural. Geologia USP, Série Científica, 14(1):6-80.

Roldan, L.F. 2007. Tectônica rúptil Meso-Cenozóica na região do Domo de Lages. São Paulo, 131p. Dissertação de Mestrado, Programa de Pós-Graduação em Geoquímica e Geotectônica, Instituto de Geociências, Universidade de São Paulo.
Roldan, L.F., Machado, R., Steiner, S.S. \& Warren L.V. 2010. Análise de Lineamentos Estruturais no Domo de Lages (SC) com uso de Imagens de Satélite e Mapas de Relevo Sombreado. Geologia USP, Série Científica, 10(2):57-72.

Rostirolla, S.P., Assine, M.L., Fernandes, L.A. \& Artur P.C. 2000. Reativação de paleolineamentos durante a evolução da Bacia do Paraná - o exemplo do alto estrutural de Quatiguá. Revista Brasileira de Geociências, 30(4):639-648.

Scherer, C.M.S. \& Lavina, E.L. 2006. Stratigraphic evolution of a fluvial-eolian succession: The example of the Upper Jurassic-Lower Cretaceous Guará and Botucatu formations, Paraná Basin, Southernmost Brazil. Gondwana Research, 9:475-484.

Schneider, R.L., Mühlmann, H., Tommasi, E., Medeiros, R.A., Daemon, R.F. \& Nogueira, A. A. 1974. Revisão estratigráfica da Bacia do Paraná. In: CONGRESSO BRASILEIRO DE GEOLOGIA, 28, Porto Alegre, 1974. Anais... Porto Alegre, SBG, v. 1, p.41-65.

Silva, M.A.S., Leites, S.R \& Caruso Jr., F. 2000. Programa levantamentos geológicos básicos do Brasil. Criciúma, Folha SH.22-X-B. Estado de Santa Catarina. Escala 1:250.000. CPRM, Brasília.

Soares P.C. 1991. Tectônica sinsedimentar cíclica na Bacia do Paraná: controles. Curitiba, 148 p. Tese (Professor Titular), Universidade Federal do Paraná.

Stica, J.M., Zalán, P.V. \& Ferrari, A.L. 2014. The evolution of rifting on the volcanic margin of the Pelotas Basin and the contextualization of the Paraná-Etendeka LIP in the separation of Gondwana in the South Atlantic. Marine and Petroleum Geology, 50:1-21.

Strugale, M., Rostirolla, S.P., Mancini, F., Portela Filho, C.V., Ferreira, F.J.F. \& Freitas, R.C. 2007. Structural framework and Mesozoic-Cenozoic evolution of Ponta Grossa Arch, Paraná Basin, southern Brazil. Journal of South American Earth Sciences, 24:203-227. 2007.

Süffert, T. 1976. Projeto carvão em Araranguá-Torres: relatório final. Porto Alegre: CPRM, v.1,71p. Waichel, B.L., Lima, E.F., Viana, A.R., Scherer, C.M., Bueno, G.V. \& Dutra, G. 2012. Stratigraphy and volcanic facies architecture of the Torres Syncline, Southern Brazil, and its role in understan- 
ding the Paraná-Etendeka Continental Flood Basalt Province. Journal of Volcanology and Geothermal Research, 215-216:74-82.

Wildner, W., Camozzato, E., Toniolo, J.A., Binotto, R.B., Iglesias, C.M.F. \& Laux, J.H. 2014. Mapa Geológico do Estado de Santa Catarina. Programa Geologia do Brasil, Superintendência Regional de Porto Alegre, v.1, escala 1:500.000.

Zalán, P.V., Wolff, S., Conceiç̧ão, J.C.J, Astolfi, M.A.M., Vieira, I.S., Appi, V.T. \& Zanotto, O.A. 1987. Tectônica e sedimentação da Bacia do Paraná. In: SIMPÓSIO SUL-BRASILEIRO DE GEOLOGIA, 3, Curitiba, 1987. Anais...Curitiba, SBG, v.1, p. 441477.

Zerfass, H., Chemale Jr., F., Schultz, C.L. \& Lavina, E. 2003. Tectonics and sedimentation in Southern South America during Triassic. Sedimentary Geology, 166:265-292.

Zerfass, H., Chemale Jr., F. \& Lavina, E. 2005. Tectonic Control of the Triassic Santa Maria Supersequence of the Paraná Basin, southernmost Brazil and its correlation to the Waterberg Basin, Namibia. Gondwana Research, 8:163-176. 